\title{
Checkpoint inhibitors in hematological malignancies
}

\author{
Chi Young OK (1D and Ken H. Young
}

\begin{abstract}
Inhibitory molecules such as PD-1, CTLA-4, LAG-3, or TIM-3 play a role to keep a balance in immune function. However, many cancers exploit such molecules to escape immune surveillance. Accumulating data support that their functions are dysregulated in lymphoid neoplasms, including plasma cell myeloma, myelodysplastic syndrome, and acute myeloid leukemia. In lymphoid neoplasms, aberrations in 9p24.1 (PD-L1, PD-L2, and JAK2 locus), latent Epstein-Barr virus infection, PD-L1 3'-untranslated region disruption, and constitutive JAK-STAT pathway are known mechanisms to induce PD-L1 expression in lymphoma cells. Clinical trials demonstrated that PD-1 blockade is an attractive way to restore host's immune function in hematological malignancies, particularly classical Hodgkin lymphoma. Numerous clinical trials exploring PD-1 blockade as a single therapy or in combination with other immune checkpoint inhibitors in patients with hematologic cancers are under way. Although impressive clinical response is observed with immune checkpoint inhibitors in patients with certain cancers, not all patients respond to immune checkpoint inhibitors. Therefore, to identify best candidates who would have excellent response to checkpoint inhibitors is of utmost importance. Several possible biomarkers are available, but consensus has not been made and pursuit to discover the best biomarker is ongoing.
\end{abstract}

Keywords: PD-1, PD-L1, PD-L2, CTLA-4, Immune checkpoint, Hematologic malignancies

\section{Background}

The hallmarks of cancer are constant proliferative signaling, evasion of growth suppressors, resistance to cell death, replicative immortality, induction of angiogenesis and activating invasion, and metastasis [1]. The dysregulated cellular processes in cancer cells are in tandem with accumulation of variable genetic alterations and consequent expression of tumor neoantigens which are not present in normal cells [2]. In ideal state, immune cells recognize these new antigens and kill the cancer cells. The whole process is elegantly explained by Chen and Mellman with the concept of the cancer-immunity cycle, which consists of several steps [3]. Firstly, dissemination of cancer neoantigens to tumor microenvironment (TME) occurs following cancer cell death (step 1). Afterwards, the released cancer neoantigens are captured and processed by antigen presenting cells, i.e., dendritic cells, where the processed neoantigens are presented as a complex with major histocompatibility complex (MHC) I or II

\footnotetext{
* Correspondence: cok@mdanderson.org

Department of Hematopathology, The University of Texas MD Anderson Cancer Center, 1515 Holcombe Boulevard, Houston, TX 77030-4009, USA
}

molecules (step 2). The following step is priming and activation of effector $\mathrm{T}$ cell against the cancer neoantigens (step 3). Owing to higher density of antigen presenting cells in lymphoid organs, the second and third steps mostly occur in peripheral lymphoid organs. Following the priming and activation, the activated effector $\mathrm{T}$ cells then migrate to the tumor site via blood vessels (step 4). When the activated effector T cells arrive in the vicinity of the tumor site, they pass through endothelial cells and infiltrate the tumor microenvironment (step 5). Once successfully infiltrated, the activated effector $\mathrm{T}$ cells bind cancer cells recognizing cancer neoantigens presented on MHC I molecule (step 6). Finally, the activated effector T cells induce apoptosis of the cancer cells by releasing cytotoxic molecules including granzyme or perforin via FasFas ligand interaction (step 7). Oftentimes, cancer cells or immunosuppressive cells in the TME provide immune inhibitory signals lest effector $\mathrm{T}$ cells function properly.

In the context of the cancer-immunity cycle, checkpoint inhibitors aim to reset or reinstate dysfunctional effector $\mathrm{T}$ cells. Clinical studies using checkpoint inhibitors have shown significant responses in various cancers [4-7]. In 
this review, we discuss biology of immune inhibitory molecules, their roles in hematological cancers, different types of checkpoint inhibitors, clinical trials on patients with hematologic cancers, and search for biomarkers in checkpoint inhibitor therapy.

\section{Maint text}

\section{Biology of immune inhibitory molecules}

For proper $\mathrm{T}$ cell activation, two separate signals are required (Fig. 1) [8]. The first signal is mediated by antigen-dependent $\mathrm{T}$ cell receptor (TCR) binding to the major histocompatibility complex (MHC) molecule of an antigen-presenting cell (APC). The second signal is antigen-independent, co-stimulatory, or co-inhibitory signal delivered by the APCs. The second signal modulates TCR signaling and determines the T cell's fate. Several co-stimulatory or co-inhibitory molecules on $\mathrm{T}$ cells with their respective ligands are collectively known as B7CD28 family. The prototypical co-stimulatory molecule is CD28 on resting naïve T cells, which induces cell-cycle progression, interleukin-2 (IL-2) production, and clonal expansion is constitutively expressed in resting naïve $\mathrm{T}$ cells [9]. Without co-stimulatory second signals, T cells fall into anergy. On the other hand, cytotoxic T-lymphocyte antigen-4 (CTLA-4) is a co-inhibitory receptor on T cells that induces $\mathrm{T}$ cell tolerance [10]. Additional second signal molecules include programmed death-1 (PD-1), lymphocyte activation gene-3 (LAG-3, CD223), T cell immunoglobulin and mucin domain-containing protein-3 (TIM-3), T cell immunoreceptor with immunoglobulin and ITIM domains (TIGIT), or B- and T-lymphocyte attenuator (BTLA). In this review, we discuss biology of CTLA-4, PD-1, LAG-3, and TIM-3, dysregulation of these molecules in hematologic malignancies, clinical trials, and biomarkers.

\section{Cytotoxic T-lymphocyte antigen-4 (CTLA-4)}

CTLA-4 (also known as CD152) was first discovered by Brunet et al. (Fig. 2) [10]. It is a protein encoded by the 4-exon CTLA4 gene on chromosome 2q33.2. It belongs to the immunoglobulin superfamily, with a single immunoglobulin V-like domain containing ligand binding sites $[10,11]$. It consists of 223 amino acids, and with a calculated molecular weight of $24.6 \mathrm{kDa}$. CTLA-4 mainly resides in the cytoplasm in naïve resting $\mathrm{T}$ cells, but its expression on the surface of $\mathrm{T}$ cells can be detected within 1 or 2 days after activation [12]. On the other hand, rapid induction of CTLA-4 expression is seen in memory $\mathrm{T}$ cells upon activation, and its expression lasts longer compared with naïve resting $\mathrm{T}$ cells [13]. In regulatory $\mathrm{T}$ cells, CTLA-4 is constitutively expressed [14].

Although their functions are opposite, CLTA-4 and CD28 share the same ligand, B7-1 and B7-2. They share the MYPPPY motif for ligand binding [15]. Of note, CTLA-4 expression is 30 - to 50 -fold less than that of CD28 even in its maximum state upon activation. However, the affinity and avidity for CTLA-4 and its ligands are much greater than $\mathrm{CD} 28$ because the former homodimerizes and can bind to B7 molecules bivalently [16].

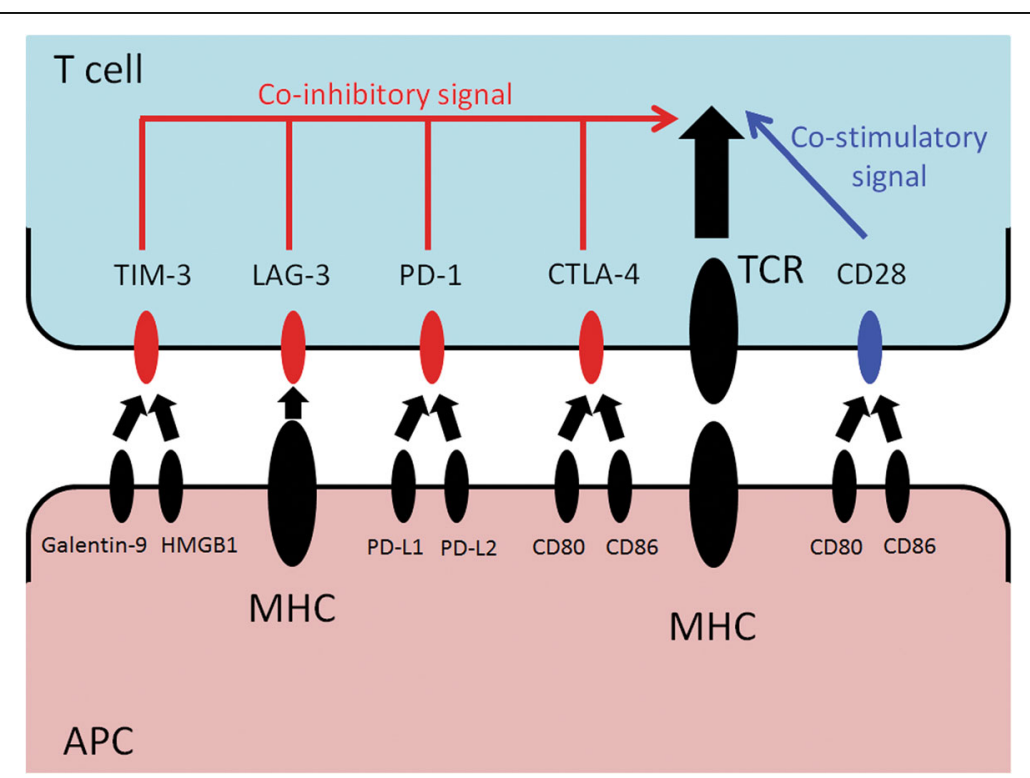

Fig. $1 \mathrm{~T}$ cell activation signals. The main signal is mediated by $\mathrm{T}$ cell receptor. Co-stimulatory signal is provided by CD28. Co-inhibitory signals are mediated by CTLA-4, PD-1, LAG-3, or TIM-3. TIM-3 T cell immunoglobulin and mucin domain-containing protein-3. LAG-3 lymphocyte activation gene-3, PD-1 programmed death-1, CTLA-4 cytotoxic T-lymphocyte antigen-4, TCR T cell receptor, HMGB1 high mobility group protein B1, MHC major histocompatibility complex, PD-L1 programmed death-ligand 1, PD-L2 programmed death-ligand 2 


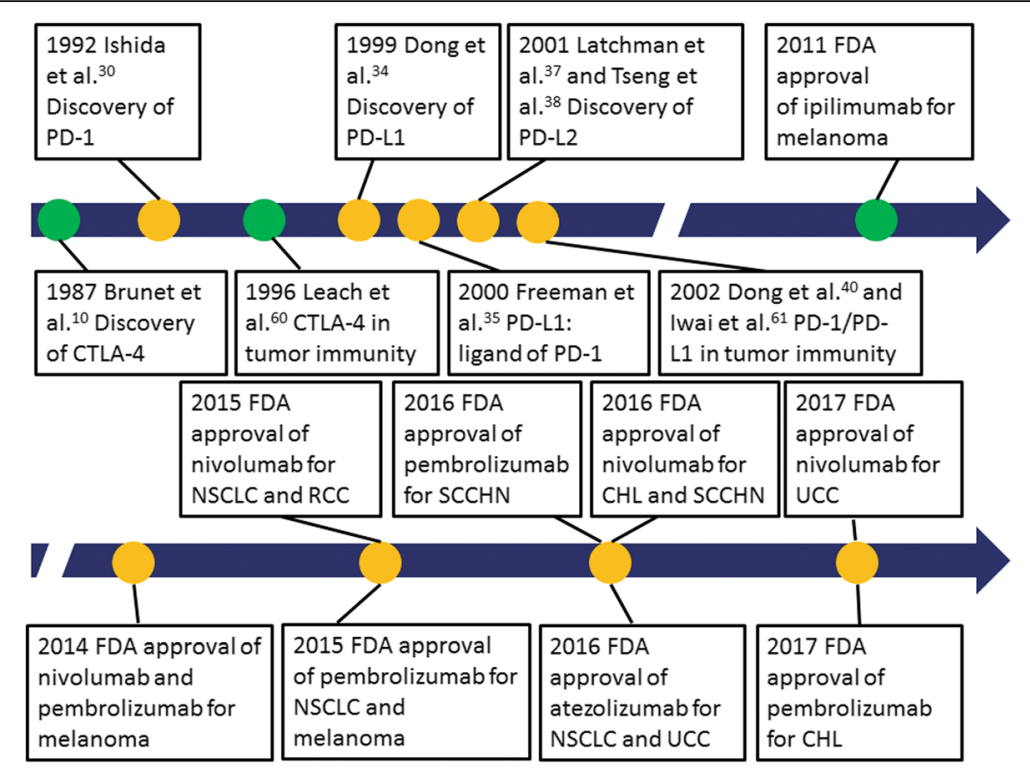

Fig. 2 From discovery for immunocheckpoints to FDA approval of immunocheckpoint inhibitors. CHL classical Hodgkin lymphoma, NSCLC non-small cell lung cancer, RCC renal cell carcinoma, SCCHN squamous cell carcinoma of the head and neck, UCC urothelial carcinoma

Upon activation by ligand binding, CTLA-4 molecules migrate from the cytoplasm to the cell surface, and this migration is dependent on the strength of $\mathrm{T}$ cell receptor signaling and phosphorylation of the $\mathrm{Y}^{165} \mathrm{VKM}$ motif in the cytoplasmic domain of CTLA-4 [17-20]. Furthermore, redistribution of CTLA-4 to the immunological synapse was shown to be highly dependent on B7-1, but only slightly dependent on B7-2 [21].

$\mathrm{T}$ cell inactivation by CTLA- 4 can be explained by two mechanisms. Once redistribution of CTLA-4 to the proximity of immunological synapse occurs, it can sequester B7-1/B7-2 owing to its higher avidity and affinity so that the CD28-mediated co-stimulatory signal would be reduced (competitive antagonism) [22]. The second mechanism is for CTLA-4 to deliver an inhibitory signal via the cytoplasmic tail. Although the precise mechanism is not unequivocally determined, CTLA-4 signal inhibits nuclear accumulation of activator protein 1 (AP-1), NF- $\mathrm{kB}$, and nuclear factor of activated T cells (NFAT) in activated $T$ cells $[23,24]$. Furthermore, CTLA- 4 halts cell cycle progression by direct inhibition of cyclin-dependent kinase 4 (CDK4), CDK6, and cyclin D3 [25]. CTLA-4 also selectively inactivates microtubule-associated protein kinase (MAPK), extracellular signal-regulated kinase-1 (ERK), and c-Jun NH2-terminal kinase (JNK), which are required for stimulation of IL-2 production [26].

The cytoplasmic tail of CTLA-4 does not contain an immune receptor tyrosine-based inhibitory motif (ITIM) and does not have intrinsic enzymatic activity. Instead, CTLA-4 inhibitory effects (phosphatase activity) are thought to be mediated with other molecules including serine/threonine phosphatase PP2A and/or Src homology
2 domain-containing phosphatases (SHPs). PP2A is bound to newly synthesized CTLA-4 molecules and makes CTLA-4 inactive [27]. Upon ligand binding in the vicinity of TCR, the scaffolding subunit of PP2A is phosphorylated and PP2A is dissociated from CTLA-4. The dissociated PP2A inhibits the phosphatidylinositol 3-kinase (PI3K)/ Akt pathway via directly inactivating protein kinase $\mathrm{B} / \mathrm{Akt}$ [28]. In addition, Guntermann and Alexander demonstrated that the majority of phosphatase activity of CTLA4 was attributed to SHP-1 [29]. Because CTLA-4 lacks ITIM, which is a direct binding site of SHP-1, it is thought that adapter proteins might be needed for interaction between CTLA-4 cytoplasmic domains and SHP-1.

\section{Programmed death-1 (PD-1)}

PD-1 (also known as CD279) was first discovered by Ishida et al. from Tasuku Honjo's group in 1992 in search of a gene inducing apoptosis [30]. PD-1 is a transmembrane protein with 288 amino acids and is encoded by PDCD1 gene on chromosome 2q37.3. PD-1 contains a single immunoglobulin V-like domain, a transmembrane domain, and an intracellular domain. The intracellular domain has an ITIM (S/I/V/LxYxxI/V/L) and an immunoreceptor tyrosine-based switch motif (ITSM; TxYxxV/I) $[31,32]$. Expression of PD-1 is present in effector T cells, regulatory $\mathrm{T}$ cells (Treg), naïve and activated $\mathrm{B}$ cells, natural killer cells, myeloid dendritic cells, and monocytes with low intensity. In resting T cells, PD-1 expression is not present, but it can be induced within $24 \mathrm{~h}$ of $\mathrm{T}$ cell activation [33].

Programmed death-ligand 1(PD-L1) and programmed death-ligand 2 (PD-L2) are ligands for PD-1. Search of 
ligand for PD-1 was actively sought by Dr. Honjo's group, but PD-L1 (also known as CD274 or B7-H1) was independently discovered by Dong et al. in Lieping Chen's group in 1999 [34]. Dr. Chen's group identified a molecule named B7-H1, but was not aware it was actually a ligand to PD-1. 1 year later, Gordon Freeman's group, in collaboration with Honjo's group, discovered a ligand for PD-1 (PD-L1) and demonstrated that PDL1 is identical to B7-H1 [35]. PD-L1 is encoded by CD274 gene on chromosome 9p24.1. In non-pathologic lymphoid tissue, PD-L1 expression is observed in follicular $\mathrm{T}$ cells, macrophages, and a subset of dendritic cells. PD-L1 is also seen in placental syncytiotrophoblasts and dendritic cells/monocytes in the lung and liver [33, 34, 36]. By collaborative study in Honjo, Freeman, and Arlene Sharpe's group, PD-L2 (also known as CD273 or B7-DC) was identified in 2001 [37]. In the same year, Tseng et al. in Drew Pardoll's group independently discovered PD-L2 [38]. PD-L2 is encoded by PDCD1LG2 gene on chromosome 9p24.1. Of note, CD274 gene and PDCD1LG2 gene are $42 \mathrm{kB}$ apart from each other. Compared with PD-L1, PD-L2 expression is more restricted. It is only seen in activated $\mathrm{CD} 4^{+}$or $\mathrm{CD} 8^{+} \mathrm{T}$ cell subsets, myeloid dendritic cells, monocytes, endothelial cells, and placental syncytiotrophoblasts [39]. Expression of PD-L1 and PD-L2 can be induced by interferon gamma (IFN- $\gamma$ ), granulocyte macrophage colony-stimulating factor (GM-CSF), and IL-4 [37, 40-42].

PD-1 negatively regulates IL-2 production and T cell proliferation $[43,44]$. Upon ligand binding, ITIM and ITSM in the cytoplasmic domain of PD-1 are phosphorylated by the Src-family tyrosine kinases and SHPs are further recruited to the phosphorylated tyrosine residue. SHPs dephosphorylate downstream signal pathways including PI3K/Akt or RAS/MEK/ERK pathway, blocking cell cycle progression $[28,45,46]$. SHPs also inactivate zeta-chain-associated protein kinase 70 (ZAP70) and protein kinase $\mathrm{C}-\theta$ (PKC- $\theta)$, essential for $\mathrm{T}$ cell activation and IL-2 production, respectively [47, 48]. However, PD-1-mediated inhibitory signals can be overcome by strong $\mathrm{T}$ cell stimulation with $\mathrm{CD} 28$ or exogenous IL-2 [49].

Inhibitory function is not the only role of PD-1 pathway. Francisco and colleagues demonstrated that PDL1 converts naïve $\mathrm{CD}^{+} /$forkhead box P3 (FOXP3)- $\mathrm{T}$ cells to $\mathrm{CD}^{+} / \mathrm{FOXP}^{+}$regulatory $\mathrm{T}$ cells (Tregs) in vitro, even without transforming growth factor beta (TGF- $\beta$ ) which is a well-established stimulator of Treg induction [50]. Induction and maintenance of Tregs by PD-L1 was also shown by the same group in vivo. Although this is not an inhibitory function in cellular level, PD-1 pathway enhances immune suppression by inducing immunosuppressive Tregs in the level of organism.
While CTLA-4 and PD-1 both deliver the coinhibitory second signal, they execute their roles at different time points in the life cycle of immune response $[51,52]$. CTLA-4 functions early in the life cycle of immune response during $\mathrm{T}$ cell priming in lymphoid organs (central checkpoint) and affects the global impact on the immune system. CTLA-4:B7-1/B7-2 interaction diminishes $\mathrm{CD}^{+} \mathrm{T}$ effector cells, increases $\mathrm{CD} 4^{+} \mathrm{T}$-helper cells and enhances immunosuppressive activity of regulatory $\mathrm{T}$ cells, resulting in peripheral $\mathrm{T}$-cell tolerance or anergy [53]. CTLA-4-deficient mice developed fatal lymphoproliferation and multiorgan autoimmunity $[54,55]$. On the other hand, PD-1 plays a role in T-cell activation in peripheral tissue containing target cells (peripheral checkpoint). PD-1:PD-L1/PD-L2 interaction attenuates TCR signaling in T cells, inducing $\mathrm{T}$ cell exhaustion. PD1-deficient mice developed lupus-like autoimmune disease inflammation [56, 57].

These checkpoints in immune response are often exploited in many cancers including hematologic malignancies $[58,59]$. The concept that CTLA-4 blockade can be used to enhance anti-tumor activity was first shown by Leach and colleagues [60]. The role of PD-1 pathway in tumor immunity was independently shown by Dong and Iwai, promoting PD-1 blockade in cancer therapy $[40,61]$.

\section{Lymphocyte activation gene-3 (LAG-3)}

Following clinical success of targeting CTLA-4 and PD-1, other co-inhibitory molecules receive more attention; LAG-3, and TIM-3. The lymphocyte activation gene-3 (LAG-3, CD223) was discovered by Triebel and colleagues in 1990 [62]. It is encoded by 8-exon LAG3 gene, located at 12p13.31. LAG-3 has 498 amino acids and has structural similarity to $\mathrm{CD} 4$, containing one immunoglobulin-like V-type domain and three immunoglobulin-like C2-type domains. The intracellular domain of LAG-3 contains a unique KIEELE motif, which is essential for $\mathrm{T}$ cell modulation by LAG-3 [63]. Expression of LAG-3 is present in activated $\mathrm{T}$ cells, NK cells, activated B cells, and plasmacytoid dendritic cells $[62,64,65]$. The major ligands of LAG-3 are class II MHC molecule on APCs and liver and lymph node sinusoidal endothelial cell Ctype lectin (LSECtin) on tumor cells or hepatocytes [66]. LAG-3 is a negative regulator in CD4 and CD8 T cell expansion in vitro as well as in vivo [67]. However, precise mechanisms remain to be elucidated. Co-expression of LAG-3 and PD-1 has been seen in tumor infiltrating lymphocytes (TILs) in tumor mouse models as well as human tissue, suggesting its role similar to PD-1 [68-70]. Inhibition of both PD-1 and LAG-3 showed augmented anti-tumor activity of $\mathrm{CD}^{+} \mathrm{T}$ cells compared to targeting either of them $[68,70]$. 
T cell immunoglobulin and mucin domain-containing protein-3 (TIM-3)

$\mathrm{T}$ cell immunoglobulin and mucin domain-containing protein-3 (TIM-3) was discovered by Monney and colleagues in 2002 [71]. TIM-3 is also called hepatitis A virus cellular receptor 2 (HAVCR2) and is encoded by HAVCR2 gene. $H A V C R 2$ is located at $5 \mathrm{q} 33.3$ and consists of seven exons. TIM-3 is a transmembrane protein, containing signal peptide sequence, immunoglobulin-like V-type domain, mucin domain, and cytoplasmic tail [71]. TIM-3 expression is present in cytotoxic $\mathrm{T}$ cells, $\mathrm{T}$ helper 1 cells, regulatory $\mathrm{T}$ cells, NK cells, monocytes, and dendritic cells. Ligands of TIM-3 are many, including galectin-9, high mobility group protein B1 (HMGB1), and phosphatidyl serine [72, 73]. In the absence of ligands, BAT3 (HLA$\mathrm{B}$ associated transcript 3 ) is bound to tyrosine residues in the cytoplasmic domain, forming a complex with TIM-3. Upon bindings to ligands, BAT3 is dissociated from the tyrosine residues and FYN, which can induce $T$ cell anergy, could replace them [74, 75]. Similar to LAG-3, coexpression of TIM-3 and PD-1 was observed in $\mathrm{CD}^{+}$ TILs [76, 77]. Interestingly, TILs with PD-1-/TIM-3- and showed the most severe dysfunction, compared to TILs with PD-1 ${ }^{+} /$TIM-3- (weak dysfunction) or TILs with PD $-1^{+} /$TIM $^{+} 3^{+}$(good function) $[76,78]$. Although tyrosine residues in the cytoplasmic domain of TIM-3 are thought to cooperate with downstream signaling pathways, precise mechanisms are yet to be determined. Targeting TIM-3 showed significant anti-tumor activity in tumor mouse models [79]. Inhibition of both PD-1 and TIM-3 also demonstrated enhanced anti-tumor activity of $\mathrm{CD} 8^{+}$TILs [76].

\section{Aberrancies in immune checkpoint molecules in hematological malignancies Lymphomas}

CTLA-4 expression is upregulated in patients with peripheral T-cell lymphoma, mycosis fungoides, and Sézary syndrome, but not seen in B-cell lymphoma [80-82]. CTLA4-CD28 rearrangement is present in a subset of patients with angioimmunoblastic T-cell lymphoma, extranodal NK/T-cell lymphoma, peripheral T-cell lymphoma, not otherwise specified, Sézary syndrome, and adult T-cell leukemia/lymphoma [83-86]. The rearrangement generates a fusion protein including the extracellular and transmembrane domains of CTLA4 and the cytoplasmic domain of CD28, which mediates activating $\mathrm{T}$ cell signals via AKT and MAPK pathways [84].

PD-L1 or PD-L2 expression in tumor cells would provide immune escape signals. PD-L1 expression can be induced by extrinsic signals (e.g., IFN- $\gamma$ ) secreted from tumor-infiltrating lymphocytes (TILs) or by intrinsic signals $[4,87]$. The former can be represented by $\mathrm{T}$ cellrich, histiocyte-rich large B cell lymphomas (TCHRBCLs), which is characterized by few malignant $\mathrm{B}$ cells in the background of dense population of $\mathrm{CD}^{+} \mathrm{T}$ cell and histiocytes [88]. Heterogeneous PD-L1 expression is usually seen in the interface between malignant B cells and inflammatory background. Of note, histiocytes adjacent to lymphoma cells also show strong PD-L1 expression in TCHRBCL, suggesting that both tumor cells and background inflammatory cells provide immune escape signals [89].

On the other hand, relatively homogenous expression of PD-L1 is present by intrinsic signals. So far, four mechanisms in intrinsic signals have been reported in lymphoid neoplasms. Firstly, copy number alterations (amplifications or gains) and/or translocations involving 9p24.1/PD-L1/PD-L2 are associated with PD-L1 overexpression in tumor cells of classical Hodgkin lymphoma (CHL), primary mediastinal large B cell lymphoma (PMBL), Epstein-Barr virus (EBV)-negative primary central nervous system lymphoma (PCNSL), primary testicular lymphoma (PTL), and in a subset of diffuse large B cell lymphoma (DLBCL) [90-94]. Of note, amplification of 9p24.1 not only increases the genetic dosage of $P D-L 1 /$ $P D-L 2$ but also induces JAK2 amplification and, consequently, enhancement of Janus kinase/signal transducer and activator of transcription (JAK/STAT) signaling [90]. Because $P D-L 1$ has a promoter that is responsive to the JAK/STAT signaling pathway, extra signaling for PD-L1 expression is present.

Secondly, PD-L1 expression can be induced by EBV infection. EBV latent membrane protein 1 (LMP1) activates the JAK/STAT pathway and the transcription factor AP-1 [95]. The relationship between JAK/STAT pathway and PD-L1 promoter was already discussed. PD-L1 enhancer can be stimulated by AP-1 $[96,97]$. In one study, PD-L1 expression is seen in all cases of EBV-positive DLBCL $\left(\mathrm{EBV}^{+} \mathrm{DLBCL}\right)$ and EBV-positive immunodeficiencyrelated DLBCL [89]. Other EBV-associated lymphoproliferative disorders including $\mathrm{EBV}^{+}$post-transplant lymphoproliferative disorder, plasmablastic lymphoma, primary effusion lymphoma, and extranodal NK/T cell lymphoma express PD-L1 [89, 97, 98].

The third mechanism was discovered by Kataoka and colleagues [99]. PD-L1 3'-untranslated region (UTR) disruption was found in a subset of DLBCL and adult T cell leukemia/lymphoma patients. The 3'-UTR disruption produces truncated PD-L1 protein, which was only found using antibody directed against the extracellular domain but not when using an antibody directed against the cytoplasmic domain. The frequency of 3' -UTR disruption in other lymphoid neoplasms remains to be elucidated.

Lastly, PD-L1 expression can be induced by constitutive activation of the JAK/STAT pathway. In anaplastic lymphoma kinase-positive anaplastic large cell lymphoma with 
NPM-ALK rearrangement, the fusion transcript can induce PD-L1 expression mediated by activated STAT3 [100]. JAK/STAT pathway is also enhanced in DLBCL activated $\mathrm{B}$ cell-like $(\mathrm{ABC})$ phenotype, which more commonly expresses PD-L1 compared to germinal center $\mathrm{B}$ cell-like (GCB) DLBCL [101]. PD-L1 expression is not generally present in other lymphoid neoplasms $[102,103]$.

PD-L2 expression is present in lymphoid neoplasms with abnormalities in 9p24.1/PD-L1/PD-L2 [91, 104, 105]. The only exception is DLBCL, in which $P D-L 2$ 's expression of RNA and protein is not associated with cytogenetic abnormalities in 9p24.1 [93]. PD-L2 expression is not associated with EBV infection or $3^{\prime}$-UTR disruption in the $P D-L 1$ gene $[99,102]$.

Given the biology of PD-1 pathway, PD-1 expression can be best examined in the microenvironment of lymphoid neoplasms. PD-1 expression in TILs has been reported in follicular lymphoma and nodular lymphocyte predominant Hodgkin lymphoma [106, 107]. Since both neoplasms arise from germinal center B cells, it is not surprising that their microenvironments mimic their normal counterparts. Similarly, PD-1-expressing TILs are also correlated with GCB DLBCL [94]. The presence of PD-1 ${ }^{+}$TILs in lymphoid neoplasms could indicate cell-of-origin because PD- $1^{+}$TILs in follicular lymphoma (FL) and DLBCL is associated with a favorable prognosis $[94,106]$. This is in contrast with solid tumors, in which presence of PD- $1^{+}$TILs is associated with poor prognosis $[108,109]$.

\section{Plasma cell myeloma (PCM)}

CTLA4 gene overexpression was observed in bone marrow sample from patients with PCM, suggesting additional immune-evasive signals are mediated with CTLA-4 in T cells [110]. A recent study showed that low expression of PD-1, CTLA-4, LAG-3, and TIM-3 is present on $\mathrm{T}$ cell clones in bone marrow and peripheral blood samples of myeloma patients, suggesting the $\mathrm{T}$ cells are not exhausted [111].

PD-L1 expression in myeloma cells and myelomapropagating pre-plasma cells detected by flow cytometry has been reported in several studies [112-115]. Similar to $\mathrm{CHL}$, increases in copy number of $P D-L 1$ correlates with PD-L1 protein expression in myeloma cells [112]. However, one study demonstrated that there was no difference regarding PD-L1 expression between normal plasma cells from healthy donors and malignant plasma cells from patients with newly diagnosed monoclonal gammopathy of undetermined significance (MGUS) or PCM [116]. Having said that, available data supports that PD-1 pathway is implicated in development of plasma cell myeloma. Bone marrow myeloma burden and serum lactate dehydrogenase level was higher in patients with PD-L1 expression in myeloma cells compared to patients without
PD-L1 expression [113]. PD-L1-expressing myeloma cells are resistant to melphalan [117]. High serum soluble PD-L1 was associated with worse progression-free survival (PFS) [118]. PD-L1 expression is higher in patients with relapsed refractory plasma cell myeloma [113]. An in vitro study demonstrated that myeloma cells with expression of PD-L1 could produce exhausted $\mathrm{T}$ cells $\left(\mathrm{CD}^{+/} \mathrm{PD} 1\right.$ ${ }^{+/}$TIM- $3^{+}$, instead of functional cytotoxic T cells [119]. Furthermore, co-culture of primary myeloma cells with $\mathrm{CD}^{+} / \mathrm{CD} 25-/ \mathrm{FOXP} 3-\mathrm{T}$ cells induced increased amount of inducible Tregs $\left(\mathrm{CD}^{+} / \mathrm{CD} 25^{+/} \mathrm{FOXP}^{+}\right)$[120]. The tumor microenvironment (TME) of plasma cell myeloma is conducive to immune evasion. PD-1 overexpression was observed in $\mathrm{T}$ cells in patients with newly diagnosed PCM and relapsed refractory PCM [112, 116, 121]. PD-L1 expression can be induced in myeloma cells when cultivated with autologous stromal cells or human stromal cell line (HS-5) [113]. Interestingly, PD-1 expression in T cells was normalized after stem cell transplant. Additionally, PD-L1 expression is present in plasmacytoid dendritic cells or myeloid-derived suppressor cells in the TME of patients with PCM $[122,123]$. PD-1 blockade showed improved survival in a myeloma murine model [119]. Unlike PD-L1, PD-L2 expression is not present in myeloma cells [112].

\section{Myeloid neoplasms}

CLTA-4 plays a role in immune escape of AML. Using a murine myelogenous leukemia cell line $(\mathrm{C} 1498)$ with expression of either CD80 or CD86, LaBelle et al. found that progressive tumor growth of C1498/CD80, but complete regression of C1498/CD86 after in vivo injection in naïve mice. They demonstrated that immune escape of C1498/CD80 is dependent on CTLA-4 [124]. A mouse model of relapsed AML study demonstrated that CTLA-4 blockade enhanced CTL-mediated killing of residual leukemic cells [125]. A CTLA-4 polymorphism CT60 AA genotype, located in the 3 '-UTR of CTLA4 gene, was shown to be associated with relapse in AML patients [126].

Preclinical studies demonstrated that PD-1 pathway was dysregulated in acute myeloid leukemia (AML). Murine leukemic cell C1498 shows low level PD-L1 expression when grown in vitro, but demonstrates upregulation of PD-L1 expression when grown in vivo, suggesting the microenvironment is conducive to expression of PD-L1 in leukemic cells [127]. Tregs and $\mathrm{CD} 8^{+} \mathrm{T}$ cells with PD-1 expression significantly increased in the liver where C1498 leukemic cells disseminate following C1498 inoculation [128]. Similar finding is also observed in the bone marrow of AML patients [129]. Tregs have suppressive effect on $\mathrm{CD}^{+} \mathrm{T}$ cell proliferation and secretion of IFN- $\gamma$ from $\mathrm{CD}^{+}{ }^{+} \mathrm{T}$ cells. However, in PD-1 knock-out (KO) mice or in wild-type mice injected with anti-PD-L1 antibody, the 
suppressive effect of Tregs was abrogated [128]. When C1498 leukemia cells were inoculated to PD-1 KO mice, enhanced anti-tumor response was observed with longer survival compared with C1498 inoculation to wild-type mice $[127,128]$. Similar anti-tumor activity was seen with in vivo administration of anti-PD-L1 antibody to C1498challenged wild-type mice $[127,128]$. In human, mRNA expression of PD-L1 and PD-L2 is observed in many AML cell lines. However, PD-1 and CTLA-4 mRNAs were only detected in KG-1 cells [130].

Clinical data also supports dysregulated PD-1 pathway in AML. Compared to healthy individuals, PD-1 expression on $\mathrm{T}$ cells was significantly higher in patients with AML [131]. By quantitative polymerase chain reaction (Q-PCR), upregulation ( $\geq$ twofold) of PD-L1 and PDL2 mRNA in CD34-positive cells was observed in 36 and $12 \%$ of patients with myelodysplastic syndrome (MDS) [130]. Similarly, upregulation of abovementioned mRNAs in CD34-positive cells were seen in 25 and 33\% of patients with AML, respectively. By immunohistochemistry, PD-L1 protein expression in leukemic blasts was seen in $20 \%$ of patients with MDS, chronic myelomonocytic leukemia, or AML. Of interest, upregulation of PD-L1, PD-L2, PD-1, and CLTA-4 was observed in $66 \%$ of patients with myeloid neoplasms who underwent epigenetic therapy.
In addition to PD-1 pathway and CTLA-4, another immune inhibitory molecule, TIM-3, is explored. Both human and mouse AML cells express galectin-9, a ligand of TIM-3. In a mouse model, exhausted $\mathrm{T}$ cells coexpressing PD-1 and TIM-3 were found, and they have reduced production of INF- $\gamma$, TNF- $\alpha$, and IL- 2 in reaction to their ligands-expressing AML cells. Blocking PD-1 or TIM-3 alone was not sufficient to reduce tumor burden, but combined blockade showed increased tumor rejection and improved survival [132]. The role of immune escape function of TIM-3 is also seen in AML patients as well. TIM-3 in bone marrow $\mathrm{T}$ cells is more frequently present in relapsed AML patients compared to those in remission or healthy donors [133].

\section{Role of checkpoint inhibition in hematological malignancies Lymphomas}

CHL is the most heavily studied lymphoid neoplasm regarding PD-1 blockade. Nivolumab (Opdivo ${ }^{\circ}$, BristolMyers Squibb) is a fully humanized IgG4 anti-PD-1 monoclonal antibody. A phase $1 \mathrm{~b}$ study demonstrated that nivolumab has acceptable safety profile and substantial clinical activity in patients with relapsed/refractory CHL (NCT01592370) (Table 1) [134]. A subsequent phase 2 study with nivolumab (CheckMate 205 cohort B

Table 1 Notable ongoing clinical trials in hematological malignancies

\begin{tabular}{|c|c|c|c|c|c|}
\hline Malignancies & Clinical trial \# & Phase & Drug & Study description & Other name \\
\hline \multirow[t]{5}{*}{ Lymphoid neoplasm } & NCT02181738 & 2 & Nivolumab & Clinical activity of anti-PD-1 antibody in R/R CHL patients & CheckMate 205 \\
\hline & NCT01953692 & 2 & Pembrolizumab & Clinical activity of anti-PD-1 antibody in R/R CHL patients & KEYNOTE-013 \\
\hline & NCT02857426 & 2 & Nivolumab & Anti-PD-1 antibody in R/R PCNSL and PTL & \\
\hline & NCT02576990 & 2 & Pembrolizumab & Anti-PD-1 antibody in R/R PMBL & KEYNOTE-170 \\
\hline & NCT02220842 & 1 & Atezolizumab & $\begin{array}{l}\text { Anti-PD-L1 antibody in combination with anti-CD20 antibody } \\
\text { to R/R DLBCL or FL }\end{array}$ & \\
\hline \multirow[t]{5}{*}{ Plasma cell neoplasm } & NCT02036502 & 1 & Pembrolizumab & $\begin{array}{l}\text { Clinical activity of anti-PD-1, lenalidomide and low-dose } \\
\text { dexamethasone in R/R PCM patients shown }\end{array}$ & KEYNOTE-023 \\
\hline & NCT02903381 & 2 & Nivolumab & $\begin{array}{l}\text { Lenalidomide, low-dose dexamethasone and anti-PD-1 antibody } \\
\text { in smoldering PCM patients }\end{array}$ & \\
\hline & NCT01592370 & 1 & Nivolumab & Clinical activity of anti-PD-1 antibody in R/R PCM patients & \\
\hline & NCT02726581 & 3 & Nivolumab & $\begin{array}{l}\text { Pomalidomide and dexamethasone with or without anti-PD-1 } \\
\text { antibody in R/R PCM patients }\end{array}$ & CheckMate 602 \\
\hline & NCT02579863 & 3 & Pembrolizumab & $\begin{array}{l}\text { Pomalidomide and dexamethasone with or without anti-PD-1 } \\
\text { antibody in treatment-naïve PCM patients }\end{array}$ & KEYNOTE-185 \\
\hline \multirow[t]{5}{*}{ Myeloid neoplasms } & NCT02530463 & 2 & Nivolumab & HMA, ipilimumab, and anti-PD-1 antibody in MDS patients & \\
\hline & NCT01953692 & 1 & Pembrolizumab & Anti-PD-1 antibody in HMA-failed MDS patients & \\
\hline & NCT02845297 & 2 & Pembrolizumab & Anti-PD-1 with HMA in R/R AML patients & \\
\hline & NCT02275533 & 2 & Nivolumab & Anti-PD-1 antibody as post-remission therapy in AML patients & \\
\hline & NCT02117219 & 1 & Durvalumab & Anti-PD-L1 antibody, HMA, and tremelimumab in MDS patients & \\
\hline
\end{tabular}

$R / R$ relapsed refractory, $P C N S L$ primary central nervous system lymphoma, $P T L$ primary testicular lymphoma, $P M B L$ primary mediastinal large $B$ cell lymphoma, $D L B C L$ diffuse large $B$ cell lymphoma, $F L$ follicular lymphoma, $P C M$ plasma cell myeloma, HMA hypomethylating agent, MDS myelodysplastic syndrome, $A M L$ acute myeloid leukemia 
and NCT02181738) confirmed its clinical activity in relapsed/refractory CHL patients. With a median follow-up duration of 15.4 months (range 1.9-18.5 months), the objective response rate (ORR) was $68 \%$, including complete remission (CR) and partial remission (PR) rates of 8 and $60 \%$, respectively. 12-month overall survival and PFS rates were 94.9 and 54.6\%, respectively [135-137].

Pembrolizumab (Keytruda ${ }^{\circ}$, Merck \& Co.) is another fully humanized IgG4 anti-PD-1 monoclonal antibody. Similar to nivolumab, pembrolizumab was shown to have manageable safety profile and favorable clinical activity in patients with relapsed/refractory CHL (NCT01953692, KEYNOTE-013) $[138,139]$. The clinical activity of pembrolizumab in patients with relapsed/refractory CHL was substantiated with a multicohort phase 2 study, which included three different cohorts (KEYNOTE-087, NCT02453594). The objective response rate (ORR) was observed in $65-72 \%$ with complete remission (CR) rate of $22 \%$ in all cohorts [140, 141].

Considering underlying genetic aberrations, PMBL, PCNSL, and PTL are good candidates for PD-1 blockade. A phase 1b study (NCT01953692, KEYNOTE-013) with pembrolizumab included an independent cohort of 19 patients with relapsed/refractory primary mediastinal large B cell lymphoma. With a median follow-up of 11.3 months (range 3.4-27.4 months), the ORR was $41 \%$, with 2 and 5 patients achieving CR and PR, respectively. On the basis of these results, a global multicenter phase 2 trial (KEYNOTE-170, NCT02576990) is ongoing [142]. An evidence-driven pilot study of nivolumab single therapy given to five patients with relapsed/refractory PCNSL and PTL found that all patients had objective radiographic responses, with four $\mathrm{CR}$ and one PR [143]. Encouraged by this result, a multi-institutional phase 2 single-arm trial of nivolumab in patients with relapsed/refractory PCNSL and PTL is in recruitment (NCT02857426). PD-1 blockade is also tried in patients with DLBCL, follicular lymphoma, T cell lymphoma, or mycosis fungoides/Sézary syndrome (MF/SS) with variable ORR (30-40\%) (NCT01592370 and NCT02243579) $[144,145]$. Other than nivolumab and pembrolizumab, other anti-PD-1 antibodies (AMP-224, BGB-A317, MEDI0680, PDR001, PF-06801591, and REGN2810) are in the lineup of immunotherapy.

Atezolizumab (Tecentriq ${ }^{\circ}$, Genentech) is a fully humanized IgG1 anti-PD-L1 monoclonal antibody, recently approved by the US Food and Drug Administration (FDA) for treatment of metastatic non-small cell lung cancer. Preliminary result of atezolizumab in combination with obinutumumab (anti-CD20 antibody) in patients with relapsed/refractory DLBCL or FL reported good tolerability and clinical efficacy (NCT02220842) [146]. Similar studies with atezolizumab with other agents in patients with relapsed/refractory DLBCL or
FL are ongoing (NCT02729896, NCT02631577, and NCT02596971). Durvalumab (AstraZeneca) is another anti-PD-L1 antibody, approved by the FDA for treatment of bladder cancer. A few clinical trials are under way with durvalumab in patients with lymphoid neoplasms (NCT02401048, NCT02706405, and NCT02643303). Avelumab (Pfizer), CA-170 (Curis, Inc.), and BMS-936559 (Bristol-Myers Squibb) also target PD-L1, with ongoing clinical trials (NCT02603419 and NCT02812875).

Ipilimumab (Yervoy ${ }^{\circ}$, Bristol-Myers Squibb) and tremelimumab (Pfizer) are fully human monoclonal antiCTLA-4 antibodies. An early pilot study of ipilimumab single therapy in patients with relapsed/refractory B cell lymphoma demonstrated low ORR (11\%) [147]. Inspired by higher ORR in melanoma patients with ipilimumab and nivolumab combination therapy, ipilimumab is explored with other therapeutic agents in patients with lymphoid neoplasms (NCT01729806, NCT01896999, and NCT02254772). Ipilimumab could be an option to lymphoma patients who relapsed after allogeneic stem cell transplant. A phase $1 / 1 \mathrm{~b}$ trial with ipilimumab in patients with relapsed hematologic malignancies after allogeneic stem cell transplant included 11 patients with lymphomas. Among patients treated with $10 \mathrm{~kg} / \mathrm{mg}$ of ipilimumab $(n=22)$, one patient with CHL achieved a partial response and four patients (three CHLs and one cutaneous $\mathrm{T}$ cell lymphoma) showed a reduction in their tumor burden (NCT01822509) [148]. A premature data of ipilimumab in combination with nivolumab in 58 patients with lymphomas (NCT01592370, CheckMate 039) demonstrated that ORRs were 74,20 , and $9 \%$ of patients with CHL $(n=31)$, B cell lymphoma $(n=15)$, and T cell lymphoma $(n=11)$, respectively [149]. Similarly, tremelimumab is studied with other agents in patients with DLBCL (NCT02205333 and NCT02549651). Interestingly, ipilimumab was given to a Sézary syndrome patient with CTLA4-CD28 rearrangement who showed a rapid clinical response [83].

\section{Plasma cell myeloma}

A phase 1 study with nivolumab single therapy included 27 patients with relapsed/refractory PCM (NCT01592370). With the median follow-up of 65.6 weeks, stable disease was the best response in 17 (63\%) patients, which lasted a median of 11.4 weeks (range 3.1-46.1 weeks) [145]. In a different arm of the same study (NCT01592370, CheckMate 039), nivolumab and ipilimumab combination therapy was tried in seven patients with relapsed/refractory PCM [149]. Only one patient (14\%) showed stable disease and four patients died due to disease progression. A phase 3 study with pomalidomide and dexamethasone with or without nivolumab for patients with relapsed/refractory plasma cell myeloma is ongoing (NCT02726581, CheckMate 602). A notable phase 2 study with nivolumab, 
lenalidomide, and low-dose dexamethasone is underway in patients with high-risk smoldering plasma cell myeloma (NCT02903381).

A phase 1 study of pembrolizumab given in combination with lenalidomide and low-dose dexamethasone to patients with relapsed/refractory plasma cell myeloma showed responses in 20 of 40 patients (50\%), including $38 \%$ of patients who were refractory to lenalidomide (KEYNOTE-023, NCT02036502) [150, 151]. Similarly, in a phase 2 study with pembrolizumab, pomalidomide, and dexamethasone given to 48 patients with relapsed/refractory plasma cell myeloma, the ORR was 56\% (27 patients) including 4, 3, 6, and 14 patients with stringent $\mathrm{CR}$, near $\mathrm{CR}$, very good $\mathrm{PR}$, and $\mathrm{PR}$, respectively (NCT02289222) [152]. A similar, smaller scale study with the same regimen given to patients with relapsed/refractory plasma cell myeloma also showed clinical activity with acceptable toxicity [153]. A phase 3 study with pomalidomide and low-dose dexamethasone with or without pembrolizumab for patients with relapsed/refractory plasma cell myeloma is currently recruiting patients (NCT02576977 KEYNOTE-183) [154]. Another phase 3 study designed for patients with newly diagnosed, treatment naïve plasma cell myeloma, who are ineligible for autologous stem cell transplantation (NCT02579863, KEYNOTE-185) [155]. Similar to nivolumab, pembrolizumab is also tried to patients with intermediate- or high-risk smoldering plasma cell myeloma, but as a single therapy (NCT02603887).

There are several clinical trials with anti-PD-L1 antibodies as a single therapy or combined with others in patients with plasma cell myeloma (NCT01375842, NCT02431208, NCT02616640, NCT02685826, NCT0 2716805, NCT02784483, and NCT02807454), but results have not been reported yet.

Available data is limited regarding CTLA-4 blockade in patients with plasma cell myeloma. Twenty-nine patients including 6 with myeloma were enrolled in a study of ipilimumab to treat relapse after allogeneic stem cell transplant. No objective response was seen in patients with myeloma [156]. The previously described phase $1 /$ $1 \mathrm{~b}$ trial with ipilimumab in patients with relapsed hematologic malignancies after allogeneic stem cell transplant included one patient with lung plasmacytoma, who showed a partial response without progression for more than 21 months (NCT01822509) [148]. A phase 1/ 2 study of combined checkpoint inhibition with nivolumab and ipilimumab in patients with plasma cell myeloma or lymphoma who are status post autologous stem cell transplant at high risk for post-transplant recurrence is underway (NCT02681302, CPIT001). A phase 1 study of tremelimumab with durvalumab is ongoing in patients with autologous stem cell transplant for plasma cell myeloma (NCT02716805).

\section{Myeloid neoplasms}

Ipilimumab appears to be efficacious in relapsed AML patients after allogeneic stem cell transplant. The phase $\mathrm{I} / \mathrm{Ib}$ study with ipilimumab $(10 \mathrm{mg} / \mathrm{kg})$ in patients with relapsed hematologic malignancies after allogeneic stem cell transplant (NCT01822509) included 16, 2, and 1 patients with AML, MDS, and myeloproliferative neoplasm, respectively. Among 22 patients treated with $10 \mathrm{mg}$ of ipilimumab per kilogram, 5 patients (23\%) who showed a complete including 3 with leukemia cutis, 1 with myeloid sarcoma, and 1 with AML showed a complete response. Additional four patients with AML did not achieve an objective response, but showed a reduction in the tumor burden [148].

In a phase I study, patients with high risk MDS $(n=11)$ who failed with hypomethylating agents were treated with ipilimumab monotherapy. Although objective response was not reported in any patients, disease stabilization was seen in five patients (45\%) [157]. Many other clinical trials with anti-CTLA-4 antibodies are explored in patients with MDS or AML as single therapy or in combination with others (NCT01757639, NCT02117219, NCT02846376, and NCT02890329).

A single-center, phase $1 \mathrm{~b} / 2$ study of nivolumab combined with azacitidine in patients $(n=51)$ with relapsed AML demonstrated superior survival compared to historical survival data derived from patients with relapsed AML treated with azacitidine-based salvage protocols. Among 35 patients who were evaluable for response, 6 patients $(18 \%)$ with complete remission (CR) or complete remission with insufficient recovery of counts (Cri), 5 (15\%) with hematologic improvement (HI), 9 (26\%) had $50 \%$ bone marrow blast reduction, and 3 (9\%) had stable disease. Of note, 12 patients (34\%) had disease progression [158]. A preliminary result of a phase 2 study with various combinations of nivolumab, ipilimumab, and azacitidine in MDS patients (NCT02530463) was reported [159]. In the cohort of treatment-naïve MDS patients who were treated with azacitidine plus nivolumab, the ORR was $69 \%$ (9/13) with 2 CR, 5 morphologic CR and hematologic improvement (HI), and $2 \mathrm{HI}$. In the cohort of MDS patients with hypomethylating agent failure, ipilimumab single therapy showed some response (ORR 22\%). However, in the same cohort, nivolumab single therapy demonstrated no response and enrollment was stopped. Preliminary result of a similar study with pembrolizumab (KEYNOTE013, NCT01953692) in patients with MDS who failed with hypomethylating agents was also reported. The ORR was $4 \%(1 / 27)$ with no CR and 1 PR [160]. Other clinical trials of anti-PD-1 antibody in combination with hypomethylating agent(s) in patients with MDS or AML patients are ongoing (NCT02845297 and NCT02599649).

Anti-PD-1 antibody can be explored with chemotherapeutic agents in patients with AML. NCT02464657 and 
NCT02768792 are such studies. In another angle, PD-1 blockade can be tried in AML patients who are in remission (NCT02275533, NCT02532231, and NCT02708641). A phase 2 study of pembrolizumab in patients with nonfavorable risk AML who underwent lymphodepletion with fludarabine and melphalan followed by autologous transplantation will be interesting (NCT02771197).

Among anti-PD-L1 antibodies, durvalumab is actively studied in patients with MDS or AML. A phase 2 study with oral azacitidine with durvalumab in patients with MDS who failed with hypomethylating agents is underway (NCT02281084). A similar phase 2 study, but with subcutaneous azacitidine in combination with durvalumab in treatment-naïve MDS or elderly ( $\geq 65$ years) AML patients is also underway (NCT02775903). A phase 1 study with durvalumab single therapy or in combination with tremelimumab with or without azacitidine to patients with MDS is ongoing (NCT02117219).

\section{Side effects of checkpoint therapy}

Checkpoint inhibitors, like any other drugs, do not provide benefits to patients without risks. Immune-related adverse events (irAEs) are a spectrum of side effects including gastrointestinal, dermatologic, hepatic, or endocrine events. It is usually recommended for patients with grade 2 irAEs to withhold checkpoint inhibitor transiently. For patients with grade 3 or higher irAEs, checkpoint inhibitor should be stopped and treated with systemic corticosteroids ( 1 to $2 \mathrm{mg} / \mathrm{kg}$ or equivalent) daily. Other immune modulatory agents such as Infliximab can be considered for patients without improvement with steroids [161].

In general, IrAEs with anti-PD-1 antibodies are less common than anti-CTLA-4 antibody. In 298 melanoma patients treated with ipilimumab ( $3 \mathrm{mg} / \mathrm{kg})$, irAEs of any grade were reported in $85 \%$ of patients [162]. Grade 3 or higher irAEs are seen in 112 patients (38\%), diarrhea being the most common irAE followed by hepatotoxicity, dermatitis, hypophysitis, and uveitis. Approximately $1 / 3$ of patients were treated with systemic corticosteroids, but it did not affect OS or time-to-treatment failure indicating generous use of corticosteroid for irAEs. In a pooled analysis of 576 melanoma patients treated with nivolumab ( $3 \mathrm{mg} / \mathrm{kg}$ ), $71 \%$ of patients suffered irAEs of any grade [163]. Grade 3 or higher irAEs were seen in 57 (10\%) of patients including neurologic AEs, autoimmune neuropathy, central demyelination, Guillain-Barré syndrome, and involuntary muscle contractions. Similar to ipilimumab, management of irAEs with systemic corticosteroids did not affect treatment response of nivolumab. Grade 3 or higher irAEs were more common in melanoma patients who were treated with combined nivolumab and ipilimumab compared with those treated with either ipilimumab or nivolumab single therapy $(55,25$, and $16 \%$, respectively) $[164,165]$.

\section{Biomarkers related to checkpoint inhibitor therapy}

Although the clinical efficacy of anti-PD-1 therapy has been proven, not all cancer types respond to anti-PD-1 therapy. In solid tumors, immunologically responsive tumors vs. immunologically ignorant tumors are recognized based on immune cell infiltration in the TME. The former tend to be seen with numerous $\mathrm{T}$ cells in the TME (inflamed tumors) and to have a high mutational load in tandem with neoantigens with higher quantity. Immunologically responsive tumors are more likely responsive to anti-PD-1 therapy [166]. However, anti-PD-l therapy is not effective in all patients with responsive tumors and even in those with response, delayed, or mixed tumor regression can be seen [167]. Furthermore, manipulation of immune checkpoints with anti-PD-1 agents not uncommonly causes irAEs. Therefore, biomarkers to selectively identify best candidates are much needed.

Several methods are currently available (Table 2). PD-L1 expression in tumor cells assessed by immunohistochemistry has been associated with better response to anti-PD-1 therapy in solid tumors as well as in CHL $[167,168]$. However, there are different types of clones for PD-L1 immunohistochemical antibodies and standardization has not been achieved. Similarly, the serum level of soluble PD-L1 measured by enzymelinked immunosorbent assay (ELISA) can be a potential predictive biomarker in patients with DLBCL or PCM $[118,169]$. However, these patients were treated with conventional chemotherapy, so investigation targeting the PD-1 pathway must be conducted. TILs, particularly with PD-L1 expression, were associated with higher response to PD-1-targeting therapy in patients with solid tumors $[5,170]$. However, data are not available regarding TILs with PD-L1 expression in patients with lymphoma. Assessment of dynamics in immune cell profiles in the TME of biopsy samples using immunohistochemistry at different time points during the treatment schedule sheds light on the prediction of response. Chen et al. has demonstrated that immune cell profiles early in treatment, not before treatment, are predictive of treatment response. They also showed that gene expression profiling using a 795-gene NanoString panel recapitulates the result [171]. Immune cell profiles can also be evaluated with peripheral blood using flow cytometry $[172,173]$.

The higher the mutational load in cancer cells, the more neoantigens are produced in them. Neoantigens generally have high antigenicity, which attracts immune cells (inflamed tumors). High mutational load is associated with a better response to anti-PD-1 therapy [174]. 
Table 2 Potential predictive and prognostic biomarker evaluation and technologies

\begin{tabular}{|c|c|c|c|}
\hline Technology & Target cells/tissue & Purpose & Reference \\
\hline Immunohistochemistry & FFPE tissue & $\begin{array}{l}\text { Analysis of protein expression in tumor cells } \\
\text { Immune cell profiling in TME }\end{array}$ & {$[11,157]$} \\
\hline Flow cytometry & Blood, fresh/frozen tumor tissue & Analysis of different subsets of immune cells & [141] \\
\hline ELISA & Blood & $\begin{array}{l}\text { Analysis of cytokine } \\
\text { Chemokine and antibodies against tumor- } \\
\text { specific antigen }\end{array}$ & [162] \\
\hline Enzyme-linked immunospot & Blood & $\begin{array}{l}\text { Quantification of T or B cells, Analysis of } \\
\text { cytokine and chemokine }\end{array}$ & [158] \\
\hline Protein microarray & Blood & Analysis of antibody signature & [159] \\
\hline Gene expression profiling & Blood, fresh/frozen/FFPE tumor tissue & $\begin{array}{l}\text { Analysis of gene signatures in tumor/ } \\
\text { immune cells }\end{array}$ & [145] \\
\hline TCR deep sequencing & Blood & T cell receptor profiling & [160] \\
\hline NGS (WES, RNA-seq) & Fresh/FFPE tissue & $\begin{array}{l}\text { Mutational load } \\
\text { Prediction of immunogenecity of tumor } \\
\text { neoantigens }\end{array}$ & {$[92,143]$} \\
\hline Epigenomics & Blood, fresh/frozen/FFPE tumor tissue & $\begin{array}{l}\text { Analysis of immune cell specific epigenetic } \\
\text { changes }\end{array}$ & [161] \\
\hline
\end{tabular}

FFPE formalin-fixed, paraffin-embedded, TME tumor microenvironment, ELISA enzyme-linked immunosorbent assay, NGS next-generation sequencing, WES whole exome sequencing

However, the number of mutations in cancer cells does not directly correlate with the production of highquality neoantigens. A computational genomic tool has been developed to predict immunogenicity of mutagenderived neoantigens or cancer germline antigens and their binding affinity to immune cells. It can further provide prediction of response when treated with antiPD-1 or anti-CTLA-4 agents $[175,176]$. The computational genomic tool was shown to be feasible with solid tumor, yet applicability of mutational load as a biomarker in lymphomas is questionable due to lack of data $[174,177]$.

Not all of abovementioned methods can be applicable to hematologic malignancies because most data was driven from patients with solid tumors or solid tumor models. However, efforts to detect intrinsic overexpression of PD-L1 or PD-L2 are recommended to identify possible good responders to anti-PD-1/PDL1 therapy. That is, immunohistochemistry for PDL1/PD-L2 protein expression, chromosome analysis, or fluorescence in situ hybridization to detect aberrations in 9p24.1/PD-L1/PD-L2 locus or RT-PCR to detect gene rearrangements involving $P D-L 1$ or $P D-L 2$ could be a minimum step.

\section{Conclusions}

Inhibitory molecules such as PD-1, CTLA-4, LAG-3, or TIM-3 play a role to keep a balance in immune function. However, many cancers exploit such molecules to escape immune surveillance. Accumulating data support that their functions are dysregulated in lymphoid neoplasms, plasma cell myeloma, myelodysplastic syndrome, and acute myeloid leukemia. Clinical trials demonstrated that
PD-1 blockade is an attractive way to reinstate host's immune function in lymphoid neoplasms, particularly classical Hodgkin lymphoma. PD-1 blockade as a single therapy or in combination with other immune checkpoint inhibitors are explored in other hematologic cancers. Of note, not all patients respond to immune checkpoint inhibitors. Therefore, the need to identify best candidates who would have excellent response to checkpoint inhibitors is high. Several possible biomarkers are available, but consensus has not been made and pursuit to discover the best biomarker is ongoing.

\section{Abbreviations}

ABC: Activated B cell-like; ALK: Anaplastic lymphoma kinase; AML: Acute myeloid leukemia; AP-1: Activator protein 1; APC: Antigen-presenting cell; BAT3: HLA-B associated transcript 3; BTLA: B- and T-lymphocyte attenuator; CDK4: Cyclin-dependent kinase 4; CDK6: Cyclin-dependent kinase 6; CHL: Classical Hodgkin lymphoma; CR: Complete remission; CTLA4: Cytotoxic T-lymphocyte antigen-4; DLBCL, NOS: Diffuse large B-cell lymphoma, not otherwise specified; EBV: Epstein-Barr virus; ELISA: Enzymelinked immunosorbent assay; ERK: Extracellular signal-regulated kinase-1; FDA: US Food and Drug Administration; FL: Follicular lymphoma; FOXP3: Forkhead box P3; GCB: Germinal center B cell-like; GM-

CSF: Granulocyte macrophage colony-stimulating factor; HAVCR2: Hepatitis A virus cellular receptor 2; HI: Hematologic improvement; HMGB1: High mobility group protein B1; IFN-Y: Interferon gamma; IL-2: Interleukin-2; ITIM: Immune receptor tyrosine-based inhibitory motif;

ITSM: Immunoreceptor tyrosine-based switch motif; JAK/STAT: Janus kinase/ signal transducer and activator of transcription; JNK: c-Jun NH2-terminal kinase; KO: Knock-out; LAG-3: Lymphocyte activation gene 3; LMP1: EBV latent membrane protein 1; LSECtin: Liver and lymph node sinusoidal endothelial cell C-type lectin; MAPK: Microtubule-associated protein kinase; MDS: Myelodysplastic syndrome; MF/SS: Mycosis fungoides/Sézary syndrome; MGUS: Monoclonal gammopathy of undetermined significance; MHC: Major histocompatibility complex; NFAT: Nuclear factor of activated T cells; ORR: Objective response rate; PCM: Plasma cell myeloma; PCNSL: Primary central nervous system lymphoma; PD-1: Programmed death-1; PDL1: Programmed death ligand-1; PD-L2: Programmed death ligand-2; PFS: Progression-free survival; PI3K: Phosphatidylinositol 3-kinase; PKC: Protein kinase C; PMBL: Primary mediastinal large B-cell lymphoma; PP2A: Protein 
phosphatase 2; PR: Partial remission; PTL: Primary testicular lymphoma; QPCR: Quantitative polymerase chain reaction; SHP: Src homology 2 domaincontaining phosphatase; TCHRBCL: T cell rich, histiocyte-rich large B cell lymphoma; TCR: T cell receptor; TGF- $\beta$ : Transforming growth factor beta; TIGIT: T cell immunoreceptor with immunoglobulin and ITIM domains; TIL: Tumor-infiltrating lymphocyte; TIM-3: T cell immunoglobulin and mucin domain-containing protein-3; TME: Tumor microenvironment; Treg: Regulatory T cells; UTR: Untranslated region; ZAP70: Zeta-chainassociated protein kinase 70

\section{Acknowledgements}

CYO is supported by The University of Texas MD Anderson Cancer Center Institutional Research and Development Fund, an Institutional Research Grant Award. The work was partially supported by the National Cancer Institute/National Institutes of Health (R01CA138688 and 1RC1CA146299) and by MD Anderson's Cancer Center Support Grant CA016672.

\section{Funding}

There was no funding involved in this study.

\section{Availability of data and materials}

This is not applicable.

\section{Authors' contributions}

$\mathrm{CYO}$ and $\mathrm{KHY}$ reviewed available literature and wrote the manuscript. Both authors read and approved the final manuscript.

\section{Competing interests}

The authors declare that they have no competing interests.

\section{Consent for publication}

This is not applicable.

\section{Ethics approval and consent to participate}

This is not applicable.

\section{Publisher's Note}

Springer Nature remains neutral with regard to jurisdictional claims in published maps and institutional affiliations.

Received: 22 March 2017 Accepted: 2 May 2017

Published online: 08 May 2017

\section{References}

1. Hanahan D, Weinberg RA. Hallmarks of cancer: the next generation. Cell. 2011;144(5):646-74.

2. Desrichard A, Snyder A, Chan TA. Cancer neoantigens and applications for immunotherapy. Clin Cancer Res. 2016;22(4):807-12.

3. Chen DS, Mellman I. Oncology meets immunology: the cancer-immunity cycle. Immunity. 2013;39(1):1-10.

4. Garon EB, Rizvi NA, Hui R, Leighl N, Balmanoukian AS, Eder JP, Patnaik A, Aggarwal C, Gubens M, Horn L, et al. Pembrolizumab for the treatment of non-small-cell lung cancer. N Engl J Med. 2015;372(21):2018-28.

5. Herbst RS, Soria JC, Kowanetz M, Fine GD, Hamid O, Gordon MS, Sosman JA, McDermott DF, Powderly JD, Gettinger SN, et al. Predictive correlates of response to the anti-PD-L1 antibody MPDL3280A in cancer patients. Nature. 2014;515(7528):563-7.

6. Ribas A, Puzanov I, Dummer R, Schadendorf D, Hamid O, Robert C, Hodi FS, Schachter J, Pavlick AC, Lewis KD, et al. Pembrolizumab versus investigatorchoice chemotherapy for ipilimumab-refractory melanoma (KEYNOTE-002): a randomised, controlled, phase 2 trial. Lancet Oncol. 2015;16(8):908-18.

7. Hodi FS, O'Day SJ, McDermott DF, Weber RW, Sosman JA, Haanen JB, Gonzalez R, Robert C, Schadendorf D, Hassel JC, et al. Improved survival with ipilimumab in patients with metastatic melanoma. N Engl J Med. 2010:363(8):711-23.

8. Bretscher P, Cohn M. A theory of self-nonself discrimination. Science. 1970:169(3950):1042-9.

9. Coyle AJ, Gutierrez-Ramos JC. The expanding B7 superfamily: increasing complexity in costimulatory signals regulating $T$ cell function. Nat Immunol. 2001;2(3):203-9.
10. Brunet JF, Denizot F, Luciani MF, Roux-Dosseto M, Suzan M, Mattei MG, Golstein P. A new member of the immunoglobulin superfamily-CTLA-4. Nature. 1987;328(6127):267-70.

11. Metzler WJ, Bajorath J, Fenderson W, Shaw SY, Constantine KL, Naemura J, Leytze G, Peach RJ, Lavoie TB, Mueller L, et al. Solution structure of human CTLA-4 and delineation of a CD80/CD86 binding site conserved in CD28. Nat Struct Biol. 1997;4(7):527-31.

12. Perkins D, Wang Z, Donovan C, He H, Mark D, Guan G, Wang Y, Walunas T, Bluestone J, Listman J, et al. Regulation of CTLA-4 expression during T cell activation. J Immunol. 1996;156(11):4154-9.

13. Jago CB, Yates J, Camara NO, Lechler RI, Lombardi G. Differential expression of CTLA-4 among T cell subsets. Clin Exp Immunol. 2004;136(3):463-71.

14. Takahashi T, Tagami T, Yamazaki S, Uede T, Shimizu J, Sakaguchi N, Mak TW, Sakaguchi S. Immunologic self-tolerance maintained by CD25(+)CD4(+) regulatory $T$ cells constitutively expressing cytotoxic $T$ lymphocyteassociated antigen 4. J Exp Med. 2000;192(2):303-10.

15. Balzano C, Buonavista N, Rouvier E, Golstein P. CTLA-4 and CD28: similar proteins, neighbouring genes. Int J Cancer Suppl. 1992;7:28-32.

16. Stamper CC, Zhang Y, Tobin JF, Erbe DV, Ikemizu S, Davis SJ, Stahl ML, Seehra J, Somers WS, Mosyak L. Crystal structure of the B7-1/CTLA-4 complex that inhibits human immune responses. Nature. 2001;410(6828):608-11.

17. Egen JG, Allison JP. Cytotoxic T lymphocyte antigen-4 accumulation in the immunological synapse is regulated by TCR signal strength. Immunity. 2002;16(1):23-35.

18. Darlington PJ, Baroja ML, Chau TA, Siu E, Ling V, Carreno BM, Madrenas J. Surface cytotoxic T lymphocyte-associated antigen 4 partitions within lipid rafts and relocates to the immunological synapse under conditions of inhibition of T cell activation. J Exp Med. 2002;195(10):1337-47.

19. Shiratori T, Miyatake S, Ohno H, Nakaseko C, Isono K, Bonifacino JS, Saito T. Tyrosine phosphorylation controls internalization of CTLA-4 by regulating its interaction with clathrin-associated adaptor complex AP-2. Immunity. 1997:6(5):583-9.

20. Zhang Y, Allison JP. Interaction of CTLA-4 with AP50, a clathrin-coated pit adaptor protein. Proc Natl Acad Sci U S A. 1997;94(17):9273-8.

21. Pentcheva-Hoang T, Egen JG, Wojnoonski K, Allison JP. B7-1 and B7-2 selectively recruit CTLA-4 and CD28 to the immunological synapse. Immunity. 2004;21(3):401-13.

22. Carreno BM, Bennett F, Chau TA, Ling V, Luxenberg D, Jussif J, Baroja ML, Madrenas J. CTLA-4 (CD152) can inhibit T cell activation by two different mechanisms depending on its level of cell surface expression. J Immunol. 2000;165(3):1352-6.

23. Fraser JH, Rincon M, McCoy KD, Le Gros G. CTLA4 ligation attenuates AP-1, NFAT and NF-kappaB activity in activated T cells. Eur J Immunol. 1999;29(3):838-44

24. Olsson C, Riesbeck K, Dohlsten M, Michaelsson E. CTLA-4 ligation suppresses CD28-induced NF-kappaB and AP-1 activity in mouse T cell blasts. J Biol Chem. 1999;274(20):14400-5.

25. Brunner MC, Chambers CA, Chan FK, Hanke J, Winoto A, Allison JP. CTLA-4Mediated inhibition of early events of T cell proliferation. J Immunol. 1999; 162(10):5813-20.

26. Calvo CR, Amsen D, Kruisbeek AM. Cytotoxic T lymphocyte antigen 4 (CTLA4) interferes with extracellular signal-regulated kinase (ERK) and Jun $\mathrm{NH}_{2}-$ terminal kinase (JNK) activation, but does not affect phosphorylation of T cell receptor zeta and ZAP70. J Exp Med. 1997;186(10):1645-53.

27. Baroja ML, Vijayakrishnan L, Bettelli E, Darlington PJ, Chau TA, Ling V, Collins M, Carreno BM, Madrenas J, Kuchroo VK. Inhibition of CTLA-4 function by the regulatory subunit of serine/threonine phosphatase $2 \mathrm{~A}$. J Immunol. 2002;168(10):5070-8

28. Parry RV, Chemnitz JM, Frauwirth KA, Lanfranco AR, Braunstein I, Kobayashi SV, Linsley PS, Thompson CB, Riley JL. CTLA-4 and PD-1 receptors inhibit Tcell activation by distinct mechanisms. Mol Cell Biol. 2005;25(21):9543-53.

29. Guntermann C, Alexander DR. CTLA-4 suppresses proximal TCR signaling in resting human CD4(+) T cells by inhibiting ZAP-70 Tyr(319) phosphorylation: a potential role for tyrosine phosphatases. J Immunol. 2002;168(9):4420-9.

30. Ishida Y, Agata Y, Shibahara K, Honjo T. Induced expression of PD-1, a novel member of the immunoglobulin gene superfamily, upon programmed cell death. EMBO J. 1992;11(11):3887-95.

31. Daeron M, Jaeger S, Du Pasquier L, Vivier E. Immunoreceptor tyrosine-based inhibition motifs: a quest in the past and future. Immunol Rev. 2008;224:11-43.

32. El Firar A, Voisin T, Rouyer-Fessard C, Ostuni MA, Couvineau A, Laburthe M. Discovery of a functional immunoreceptor tyrosine-based switch motif in a 
7-transmembrane-spanning receptor: role in the orexin receptor OX1Rdriven apoptosis. FASEB J. 2009;23(12):4069-80.

33. Keir ME, Butte MJ, Freeman GJ, Sharpe AH. PD-1 and its ligands in tolerance and immunity. Annu Rev Immunol. 2008;26:677-704.

34. Dong H, Zhu G, Tamada K, Chen L. B7-H1, a third member of the B7 family, co-stimulates T-cell proliferation and interleukin-10 secretion. Nat Med. 1999;5(12):1365-9.

35. Freeman GJ, Long AJ, Iwai $Y$, Bourque K, Chernova T, Nishimura H, Fitz LJ, Malenkovich N, Okazaki T, Byrne MC, et al. Engagement of the PD-1 immunoinhibitory receptor by a novel B7 family member leads to negative regulation of lymphocyte activation. J Exp Med. 2000;192(7):1027-34.

36. Xerri L, Chetaille B, Serriari N, Attias C, Guillaume Y, Arnoulet C, Olive D. Programmed death 1 is a marker of angioimmunoblastic T-cell lymphoma and B-cell small lymphocytic lymphoma/chronic lymphocytic leukemia. Hum Pathol. 2008;39(7):1050-8.

37. Latchman Y, Wood CR, Chernova T, Chaudhary D, Borde M, Chernova I, Iwai Y, Long AJ, Brown JA, Nunes R, et al. PD-L2 is a second ligand for PD-1 and inhibits T cell activation. Nat Immunol. 2001;2(3):261-8.

38. Tseng SY, Otsuji M, Gorski K, Huang X, Slansky JE, Pai SI, Shalabi A, Shin T, Pardoll DM, Tsuchiya H. B7-DC, a new dendritic cell molecule with potent costimulatory properties for T cells. J Exp Med. 2001;193(7):839-46.

39. Messal N, Serriari NE, Pastor S, Nunes JA, Olive D. PD-L2 is expressed on activated human T cells and regulates their function. Mol Immunol. 2011; 48(15-16):2214-9.

40. Dong H, Strome SE, Salomao DR, Tamura H, Hirano F, Flies DB, Roche PC, Lu J, Zhu G, Tamada K, et al. Tumor-associated B7-H1 promotes T-cell apoptosis: a potential mechanism of immune evasion. Nat Med. 2002;8(8):793-800.

41. Yamazaki T, Akiba H, Iwai H, Matsuda H, Aoki M, Tanno Y, Shin T, Tsuchiya $\mathrm{H}$, Pardoll DM, Okumura K, et al. Expression of programmed death 1 ligands by murine T cells and APC. J Immunol. 2002;169(10):5538-45.

42. Curiel TJ, Wei S, Dong H, Alvarez X, Cheng P, Mottram P, Krzysiek R, Knutson $\mathrm{KL}$, Daniel B, Zimmermann MC, et al. Blockade of B7-H1 improves myeloid dendritic cell-mediated antitumor immunity. Nat Med. 2003;9(5):562-7.

43. Zhang X, Schwartz JC, Guo X, Bhatia S, Cao E, Lorenz M, Cammer M, Chen $L$, Zhang ZY, Edidin MA, et al. Structural and functional analysis of the costimulatory receptor programmed death-1. Immunity. 2004;20(3):337-47.

44. Bennett $F$, Luxenberg $D$, Ling $V$, Wang IM, Marquette $K$, Lowe $D$, Khan $N$, Veldman G, Jacobs KA, Valge-Archer VE, et al. Program death-1 engagement upon TCR activation has distinct effects on costimulation and cytokinedriven proliferation: attenuation of ICOS, IL-4, and IL-21, but not CD28, IL-7, and IL-15 responses. J Immunol. 2003;170(2):711-8.

45. Saunders PA, Hendrycks VR, Lidinsky WA, Woods ML. PD-L2:PD-1 involvement in T cell proliferation, cytokine production, and integrinmediated adhesion. Eur J Immunol. 2005;35(12):3561-9.

46. Patsoukis N, Sari D, Boussiotis VA. PD-1 inhibits T cell proliferation by upregulating p27 and p15 and suppressing Cdc25A. Cell Cycle. 2012;11(23):4305-9.

47. Sheppard KA, Fitz LJ, Lee JM, Benander C, George JA, Wooters J, Qiu Y, Jussif JM, Carter LL, Wood CR, et al. PD-1 inhibits T-cell receptor induced phosphorylation of the ZAP70/CD3zeta signalosome and downstream signaling to PKCtheta. FEBS Lett. 2004;574(1-3):37-41.

48. Isakov N, Altman A. Protein kinase C(theta) in T cell activation. Annu Rev Immunol. 2002;20:761-94.

49. Carter L, Fouser LA, Jussif J, Fitz L, Deng B, Wood CR, Collins M, Honjo T, Freeman GJ, Carreno BM. PD-1:PD-L inhibitory pathway affects both CD4(+) and CD8(+) T cells and is overcome by IL-2. Eur J Immunol. 2002;32(3):634-43.

50. Francisco LM, Salinas VH, Brown KE, Vanguri VK, Freeman GJ, Kuchroo VK, Sharpe AH. PD-L1 regulates the development, maintenance, and function of induced regulatory T cells. J Exp Med. 2009;206(13):3015-29.

51. Goodman A, Patel SP, Kurzrock R. PD-1-PD-L1 immune-checkpoint blockade in B-cell lymphomas. Nat Rev Clin Oncol. 2017;14(4):203-20.

52. Ma W, Gilligan BM, Yuan J, Li T. Current status and perspectives in translational biomarker research for PD-1/PD-L1 immune checkpoint blockade therapy. J Hematol Oncol. 2016;9(1):47.

53. Chen L, Flies DB. Molecular mechanisms of $T$ cell co-stimulation and coinhibition. Nat Rev Immunol. 2013;13(4):227-42.

54. Waterhouse P, Penninger JM, Timms E, Wakeham A, Shahinian A, Lee KP, Thompson CB, Griesser H, Mak TW. Lymphoproliferative disorders with early lethality in mice deficient in Ctla-4. Science. 1995;270(5238):985-8.

55. Tivol EA, Borriello F, Schweitzer AN, Lynch WP, Bluestone JA, Sharpe AH. LOSS of CTLA-4 leads to massive lymphoproliferation and fatal multiorgan tissue destruction, revealing a critical negative regulatory role of CTLA-4 Immunity. 1995;3(5):541-7.

56. Nishimura H, Okazaki T, Tanaka Y, Nakatani K, Hara M, Matsumori A, Sasayama S, Mizoguchi A, Hiai H, Minato N, et al. Autoimmune dilated cardiomyopathy in PD-1 receptor-deficient mice. Science. 2001;291(5502):319-22.

57. Nishimura H, Nose M, Hiai H, Minato N, Honjo T. Development of lupus-like autoimmune diseases by disruption of the PD-1 gene encoding an ITIM motif-carrying immunoreceptor. Immunity. 1999;11(2):141-51.

58. Kohnke T, Krupka C, Tischer J, Knosel T, Subklewe M. Increase of PD-L1 expressing B-precursor ALL cells in a patient resistant to the CD19/CD3bispecific $T$ cell engager antibody blinatumomab. J Hematol Oncol. 2015;8:111.

59. Schnorfeil FM, Lichtenegger FS, Emmerig K, Schlueter M, Neitz JS, Draenert R, Hiddemann W, Subklewe M. T cells are functionally not impaired in AML: increased PD-1 expression is only seen at time of relapse and correlates with a shift towards the memory $T$ cell compartment. J Hematol Oncol. 2015;8:93.

60. Leach DR, Krummel MF, Allison JP. Enhancement of antitumor immunity by CTLA-4 blockade. Science. 1996;271(5256):1734-6.

61. Iwai Y, Ishida M, Tanaka Y, Okazaki T, Honjo T, Minato N. Involvement of PD-L1 on tumor cells in the escape from host immune system and tumor immunotherapy by PD-L1 blockade. Proc Natl Acad Sci U S A. 2002;99(19):12293-7.

62. Triebel F, Jitsukawa S, Baixeras E, Roman-Roman S, Genevee C, ViegasPequignot $E$, Hercend T. LAG-3, a novel lymphocyte activation gene closely related to CD4. J Exp Med. 1990;171(5):1393-405.

63. Workman CJ, Vignali DA. The CD4-related molecule, LAG-3 (CD223), regulates the expansion of activated T cells. Eur J Immunol. 2003;33(4):970-9.

64. Kisielow M, Kisielow J, Capoferri-Sollami G, Karjalainen K. Expression of lymphocyte activation gene 3 (LAG-3) on B cells is induced by T cells. Eur J Immunol. 2005;35(7):2081-8.

65. Workman CJ, Wang Y, El Kasmi KC, Pardoll DM, Murray PJ, Drake CG, Vignali DA. LAG-3 regulates plasmacytoid dendritic cell homeostasis. J Immunol. 2009;182(4):1885-91.

66. Xu F, Liu J, Liu D, Liu B, Wang M, Hu Z, Du X, Tang L, He F. LSECtin expressed on melanoma cells promotes tumor progression by inhibiting antitumor T-cell responses. Cancer Res. 2014;74(13):3418-28.

67. Workman CJ, Dugger KJ, Vignali DA. Cutting edge: molecular analysis of the negative regulatory function of lymphocyte activation gene-3. J Immunol. 2002;169(10):5392-5.

68. Woo SR, Turnis ME, Goldberg MV, Bankoti J, Selby M, Nirschl CJ, Bettini ML, Gravano DM, Vogel P, Liu CL, et al. Immune inhibitory molecules LAG-3 and PD-1 synergistically regulate T-cell function to promote tumoral immune escape. Cancer Res. 2012;72(4):917-27.

69. Grosso JF, Goldberg MV, Getnet D, Bruno TC, Yen HR, Pyle KJ, Hipkiss E, Vignali DA, Pardoll DM, Drake CG. Functionally distinct LAG-3 and PD-1 subsets on activated and chronically stimulated CD8 T cells. J Immunol. 2009;182(11):6659-69.

70. Matsuzaki J, Gnjatic S, Mhawech-Fauceglia P, Beck A, Miller A, Tsuji T, Eppolito C, Qian F, Lele S, Shrikant P, et al. Tumor-infiltrating NY-ESO-1specific CD8+ T cells are negatively regulated by LAG-3 and PD-1 in human ovarian cancer. Proc Natl Acad Sci U S A. 2010;107(17):7875-80.

71. Monney L, Sabatos CA, Gaglia JL, Ryu A, Waldner H, Chernova T, Manning S, Greenfield EA, Coyle AJ, Sobel RA, et al. Th1-specific cell surface protein Tim-3 regulates macrophage activation and severity of an autoimmune disease. Nature. 2002;415(6871):536-41.

72. Zhu C, Anderson AC, Schubart A, Xiong H, Imitola J, Khoury SJ, Zheng XX, Strom TB, Kuchroo VK. The Tim-3 ligand galectin-9 negatively regulates $T$ helper type 1 immunity. Nat Immunol. 2005;6(12):1245-52.

73. Chiba S, Baghdadi M, Akiba H, Yoshiyama H, Kinoshita I, Dosaka-Akita H, Fujioka Y, Ohba Y, Gorman JV, Colgan JD, et al. Tumor-infiltrating DCs suppress nucleic acid-mediated innate immune responses through interactions between the receptor TIM-3 and the alarmin HMGB1. Nat Immunol. 2012;13(9):832-42

74. Davidson D, Schraven B, Veillette A. PAG-associated FynT regulates calcium signaling and promotes anergy in T lymphocytes. Mol Cell Biol. 2007;27(5):1960-73.

75. Rangachari M, Zhu C, Sakuishi K, Xiao S, Karman J, Chen A, Angin M, Wakeham A, Greenfield EA, Sobel RA, et al. Bat3 promotes $T$ cell responses and autoimmunity by repressing Tim-3-mediated cell death and exhaustion. Nat Med. 2012;18(9):1394-400. 
76. Sakuishi K, Apetoh L, Sullivan JM, Blazar BR, Kuchroo VK, Anderson AC. Targeting Tim-3 and PD-1 pathways to reverse T cell exhaustion and restore anti-tumor immunity. J Exp Med. 2010;207(10):2187-94.

77. Yang ZZ, Grote DM, Ziesmer SC, Niki T, Hirashima M, Novak AJ, Witzig TE, Ansell SM. IL-12 upregulates TIM-3 expression and induces T cell exhaustion in patients with follicular B cell non-Hodgkin lymphoma. J Clin Invest. 2012; 122(4):1271-82.

78. Fourcade J, Sun Z, Benallaoua M, Guillaume P, Luescher IF, Sander C, Kirkwood JM, Kuchroo V, Zarour HM. Upregulation of Tim-3 and PD-1 expression is associated with tumor antigen-specific CD8+ T cell dysfunction in melanoma patients. J Exp Med. 2010;207(10):2175-86.

79. Ngiow SF, von Scheidt B, Akiba H, Yagita H, Teng MW, Smyth MJ. Anti-TIM3 antibody promotes $T$ cell IFN-gamma-mediated antitumor immunity and suppresses established tumors. Cancer Res. 2011;71(10):3540-51.

80. Wong HK, Wilson AJ, Gibson HM, Hafner MS, Hedgcock CJ, Berger CL, Edelson RL, Lim HW. Increased expression of CTLA-4 in malignant T-cells from patients with mycosis fungoides - cutaneous T cell lymphoma. J Invest Dermatol. 2006;126(1):212-9.

81. Gibson HM, Mishra A, Chan DV, Hake TS, Porcu P, Wong HK. Impaired proteasome function activates GATA3 in T cells and upregulates CTLA-4 relevance for Sezary syndrome. J Invest Dermatol. 2013;133(1):249-57.

82. Xerri L, Devilard E, Hassoun J, Olive D, Birg F. In vivo expression of the CTLA4 inhibitory receptor in malignant and reactive cells from human lymphomas. J Pathol. 1997;183(2):182-7.

83. Sekulic A, Liang WS, Tembe W, Izatt T, Kruglyak S, Kiefer JA, Cuyugan L, Zismann V, Legendre C, Pittelkow MR, et al. Personalized treatment of Sezary syndrome by targeting a novel CTLA4:CD28 fusion. Mol Genet Genomic Med. 2015;3(2):130-6.

84. Yoo HY, Kim P, Kim WS, Lee SH, Kim S, Kang SY, Jang HY, Lee JE, Kim J, Kim SJ, et al. Frequent CTLA4-CD28 gene fusion in diverse types of T-cell lymphoma. Haematologica. 2016;101(6):757-63.

85. Kataoka K, Nagata Y, Kitanaka A, Shiraishi Y, Shimamura T, Yasunaga J, Totoki Y, Chiba K, Sato-Otsubo A, Nagae G, et al. Integrated molecular analysis of adult T cell leukemia/lymphoma. Nat Genet. 2015;47(11):1304-15.

86. Ungewickell A, Bhaduri A, Rios E, Reuter J, Lee CS, Mah A, Zehnder A, Ohgami R, Kulkarni S, Armstrong R, et al. Genomic analysis of mycosis fungoides and Sezary syndrome identifies recurrent alterations in TNFR2. Nat Genet. 2015;47(9):1056-60.

87. Spranger S, Spaapen RM, Zha Y, Williams J, Meng Y, Ha TT, Gajewski TF. Up-regulation of PD-L1, IDO, and T(regs) in the melanoma tumor microenvironment is driven by CD8(+) T cells. Sci Transl Med. 2013; 5(200):200ra116.

88. Blank C, Brown I, Peterson AC, Spiotto M, Iwai Y, Honjo T, Gajewski TF. PD$\mathrm{L} 1 / \mathrm{B} 7 \mathrm{H}-1$ inhibits the effector phase of tumor rejection by $\mathrm{T}$ cell receptor (TCR) transgenic CD8+ T cells. Cancer Res. 2004;64(3):1140-5.

89. Chen BJ, Chapuy B, Ouyang J, Sun HH, Roemer MG, Xu ML, Yu H, Fletcher CD, Freeman GJ, Shipp MA, et al. PD-L1 expression is characteristic of a subset of aggressive B-cell lymphomas and virus-associated malignancies. Clin Cancer Res. 2013;19(13):3462-73.

90. Green MR, Monti S, Rodig SJ, Juszczynski P, Currie T, O'Donnell E, Chapuy B, Takeyama K, Neuberg D, Golub TR, et al. Integrative analysis reveals selective 9p24.1 amplification, increased PD-1 ligand expression, and further induction via JAK2 in nodular sclerosing Hodgkin lymphoma and primary mediastinal large B-cell lymphoma. Blood. 2010;116(17):3268-77.

91. Chapuy B, Roemer MG, Stewart C, Tan Y, Abo RP, Zhang L, Dunford AJ, Meredith DM, Thorner AR, Jordanova ES, et al. Targetable genetic features of primary testicular and primary central nervous system lymphomas. Blood. 2016;127(7):869-81.

92. Twa DD, Chan FC, Ben-Neriah S, Woolcock BW, Mottok A, Tan KL, Slack GW, Gunawardana J, Lim RS, McPherson AW, et al. Genomic rearrangements involving programmed death ligands are recurrent in primary mediastinal large B-cell lymphoma. Blood. 2014;123(13):2062-5.

93. Georgiou K, Chen L, Berglund M, Ren W, de Miranda NF, Lisboa S, Fangazio M, Zhu S, Hou Y, Wu K, et al. Genetic basis of PD-L1 overexpression in diffuse large B-cell lymphomas. Blood. 2016;127(24):3026-34.

94. Kiyasu J, Miyoshi H, Hirata A, Arakawa F, Ichikawa A, Niino D, Sugita Y, Yufu $Y$, Choi I, Abe $Y$, et al. Expression of programmed cell death ligand 1 is associated with poor overall survival in patients with diffuse large B-cell lymphoma. Blood. 2015;126(19):2193-201.

95. Ok CY, Li L, Xu-Monette ZY, Visco C, Tzankov A, Manyam GC, MontesMoreno S, Dybkaer K, Chiu A, Orazi A, et al. Prevalence and clinical implications of epstein-barr virus infection in de novo diffuse large B-cell lymphoma in Western countries. Clin Cancer Res. 2014;20(9):2338-49.

96. Kieser A, Kilger E, Gires O, Ueffing M, Kolch W, Hammerschmidt W. EpsteinBarr virus latent membrane protein-1 triggers AP-1 activity via the c-Jun Nterminal kinase cascade. EMBO J. 1997;16(21):6478-85.

97. Green MR, Rodig S, Juszczynski P, Ouyang J, Sinha P, O'Donnell E, Neuberg D, Shipp MA. Constitutive AP-1 activity and EBV infection induce PD-L1 in Hodgkin lymphomas and posttransplant lymphoproliferative disorders: implications for targeted therapy. Clin Cancer Res. 2012;18(6):1611-8.

98. Bi XW, Wang H, Zhang WW, Wang JH, Liu WJ, Xia ZJ, Huang HQ, Jiang WQ, Zhang YJ, Wang L. PD-L1 is upregulated by EBV-driven LMP1 through NFkappaB pathway and correlates with poor prognosis in natural killer/T-cell lymphoma. J Hematol Oncol. 2016;9(1):109.

99. Kataoka K, Shiraishi Y, Takeda Y, Sakata S, Matsumoto M, Nagano S, Maeda T, Nagata Y, Kitanaka A, Mizuno S, et al. Aberrant PD-L1 expression through 3'-UTR disruption in multiple cancers. Nature. 2016;534(7607):402-6

100. Marzec M, Zhang Q, Goradia A, Raghunath PN, Liu X, Paessler M, Wang HY, Wysocka $M$, Cheng M, Ruggeri BA, et al. Oncogenic kinase NPM/ALK induces through STAT3 expression of immunosuppressive protein CD274 (PD-L1, B7-H1). Proc Natl Acad Sci U S A. 2008;105(52):20852-7.

101. Ok CY, Chen J, Xu-Monette ZY, Tzankov A, Manyam GC, Li L, Visco C, Montes-Moreno S, Dybkaer K, Chiu A, et al. Clinical implications of phosphorylated STAT3 expression in De Novo diffuse large B-cell lymphoma. Clin Cancer Res. 2014;20(19):5113-23.

102. Andorsky DJ, Yamada RE, Said J, Pinkus GS, Betting DJ, Timmerman JM. Programmed death ligand 1 is expressed by non-hodgkin lymphomas and inhibits the activity of tumor-associated T cells. Clin Cancer Res. 2011;17(13):4232-44.

103. Gatalica Z, Bilalovic N, Vranic S, Arguello D, Reddy S, Ghosh N. PD-L1 and PD1 Expression in Lymphomas. Blood. 2015;126(23):Abstract 3899.

104. Yamamoto R, Nishikori M, Kitawaki T, Sakai T, Hishizawa M, Tashima M, Kondo T, Ohmori K, Kurata M, Hayashi T, et al. PD-1-PD-1 ligand interaction contributes to immunosuppressive microenvironment of Hodgkin lymphoma. Blood. 2008;111(6):3220-4.

105. Shi M, Roemer MG, Chapuy B, Liao X, Sun H, Pinkus GS, Shipp MA, Freeman GJ, Rodig SJ. Expression of programmed cell death 1 ligand 2 (PD-L2) is a distinguishing feature of primary mediastinal (thymic) large B-cell lymphoma and associated with PDCD1LG2 copy gain. Am J Surg Pathol. 2014;38(12):1715-23.

106. Carreras J, Lopez-Guillermo A, Roncador G, Villamor N, Colomo L, Martinez A, Hamoudi R, Howat WJ, Montserrat E, Campo E. High numbers of tumorinfiltrating programmed cell death 1-positive regulatory lymphocytes are associated with improved overall survival in follicular lymphoma. J Clin Oncol. 2009;27(9):1470-6.

107. Nam-Cha SH, Roncador G, Sanchez-Verde L, Montes-Moreno S, Acevedo A, Dominguez-Franjo P, Piris MA. PD-1, a follicular T-cell marker useful for recognizing nodular lymphocyte-predominant Hodgkin lymphoma. Am J Surg Pathol. 2008;32(8):1252-7.

108. Thompson RH, Dong H, Lohse CM, Leibovich BC, Blute ML, Cheville JC, Kwon ED. PD-1 is expressed by tumor-infiltrating immune cells and is associated with poor outcome for patients with renal cell carcinoma. Clin Cancer Res. 2007;13(6):1757-61.

109. Kim JR, Moon YJ, Kwon KS, Bae JS, Wagle S, Kim KM, Park HS, Lee H, Moon WS, Chung MJ, et al. Tumor infiltrating PD1-positive lymphocytes and the expression of PD-L1 predict poor prognosis of soft tissue sarcomas. PLoS ONE. 2013;8(12):e82870.

110. Braga WM, da Silva BR, de Carvalho AC, Maekawa YH, Bortoluzzo AB, Rizzatti EG, Atanackovic D, Colleoni GW. FOXP3 and CTLA4 overexpression in multiple myeloma bone marrow as a sign of accumulation of CD4(+) T regulatory cells. Cancer Immunol Immunother. 2014;63(11):1189-97.

111. Suen H, Brown R, Yang S, Weatherburn C, Ho PJ, Woodland N, Nassif N, Barbaro P, Bryant C, Hart D, et al. Multiple myeloma causes clonal T-cell immunosenescence: identification of potential novel targets for promoting tumour immunity and implications for checkpoint blockade. Leukemia. 2016;30(8):1716-24.

112. Gorgun G, Samur MK, Cowens KB, Paula S, Bianchi G, Anderson JE, White RE, Singh A, Ohguchi $H$, Suzuki R, et al. Lenalidomide enhances immune checkpoint blockade-induced immune response in multiple myeloma. Clin Cancer Res. 2015;21(20):4607-18. 
113. Tamura H, Ishibashi M, Yamashita T, Tanosaki S, Okuyama N, Kondo A, Hyodo H, Shinya E, Takahashi H, Dong H, et al. Marrow stromal cells induce $\mathrm{B} 7-\mathrm{H} 1$ expression on myeloma cells, generating aggressive characteristics in multiple myeloma. Leukemia. 2013;27(2):464-72.

114. Liu J, Hamrouni A, Wolowiec D, Coiteux V, Kuliczkowski K, Hetuin D, Saudemont A, Quesnel B. Plasma cells from multiple myeloma patients express B7-H1 (PD-L1) and increase expression after stimulation with IFN\{gamma\} and TLR ligands via a MyD88-, TRAF6-, and MEK-dependent pathway. Blood. 2007;110(1):296-304.

115. Yousef S, Marvin J, Steinbach M, Langemo A, Kovacsovics T, Binder M, Kroger N, Luetkens T, Atanackovic D. Immunomodulatory molecule PD-L1 is expressed on malignant plasma cells and myeloma-propagating pre-plasma cells in the bone marrow of multiple myeloma patients. Blood Cancer J. 2015;5:e285.

116. Paiva B, Azpilikueta A, Puig N, Ocio EM, Sharma R, Oyajobi BO, Labiano S, San-Segundo L, Rodriguez A, Aires-Mejia I, et al. PD-L1/PD-1 presence in the tumor microenvironment and activity of PD-1 blockade in multiple myeloma. Leukemia. 2015;29(10):2110-3.

117. Ishibashi M, Tamura H, Sunakawa M, Kondo-Onodera A, Okuyama N, Hamada Y, Moriya K, Choi I, Tamada K, Inokuchi K. Myeloma drug resistance induced by binding of myeloma B7-H1 (PD-L1) to PD-1. Cancer Immunol Res. 2016;4(9):779-88.

118. Wang L, Wang $H$, Chen $H$, Wang WD, Chen XQ, Geng QR, Xia ZJ, Lu Y. Serum levels of soluble programmed death ligand 1 predict treatment response and progression free survival in multiple myeloma. Oncotarget. 2015;6(38):41228-36.

119. Hallett WH, Jing W, Drobyski WR, Johnson BD. Immunosuppressive effects of multiple myeloma are overcome by PD-L1 blockade. Biol Blood Marrow Transplant. 2011;17(8):1133-45.

120. Feyler S, Scott GB, Parrish C, Jarmin S, Evans P, Short M, McKinley K, Selby PJ, Cook G. Tumour cell generation of inducible regulatory T-cells in multiple myeloma is contact-dependent and antigen-presenting cellindependent. PLoS ONE. 2012;7(5):e35981.

121. Rosenblatt J, Glotzbecker B, Mills H, Vasir B, Tzachanis D, Levine JD, Joyce RM, Wellenstein K, Keefe W, Schickler M, et al. PD-1 blockade by CT-011, anti-PD-1 antibody, enhances ex vivo T-cell responses to autologous dendritic cell/myeloma fusion vaccine. J Immunother. 2011;34(5):409-18.

122. Ray A, Das DS, Song Y, Richardson P, Munshi NC, Chauhan D, Anderson KC. Targeting PD1-PDL1 immune checkpoint in plasmacytoid dendritic cell interactions with T cells, natural killer cells and multiple myeloma cells. Leukemia. 2015:29(6):1441-4.

123. Sponaas AM, Moharrami NN, Feyzi E, Standal T, Holth Rustad E, Waage A, Sundan A. PDL1 expression on plasma and dendritic cells in myeloma bone marrow suggests benefit of targeted anti PD1-PDL1 therapy. PLOS ONE. 2015;10(10):e0139867.

124. LaBelle JL, Hanke CA, Blazar BR, Truitt RL. Negative effect of CTLA-4 on induction of T-cell immunity in vivo to B7-1+, but not B7-2+, murine myelogenous leukemia. Blood. 2002;99(6):2146-53.

125. Saudemont A, Quesnel B. In a model of tumor dormancy, long-term persistent leukemic cells have increased B7-H1 and B7.1 expression and resist CTL-mediated lysis. Blood. 2004;104(7):2124-33.

126. Perez-Garcia A, Brunet S, Berlanga JJ, Tormo M, Nomdedeu J, Guardia R, Ribera JM, Heras I, Llorente A, Hoyos M, et al. CTLA-4 genotype and relapse incidence in patients with acute myeloid leukemia in first complete remission after induction chemotherapy. Leukemia. 2009;23(3):486-91.

127. Zhang L, Gajewski TF, Kline J. PD-1/PD-L1 interactions inhibit antitumor immune responses in a murine acute myeloid leukemia model. Blood. 2009;114(8):1545-52

128. Zhou Q, Munger ME, Highfill SL, Tolar J, Weigel BJ, Riddle M, Sharpe AH, Vallera DA, Azuma M, Levine BL, et al. Program death-1 signaling and regulatory $T$ cells collaborate to resist the function of adoptively transferred cytotoxic T lymphocytes in advanced acute myeloid leukemia. Blood. 2010; 116(14):2484-93.

129. Goswami M, Oetjen K, Mule MP, Sheela S, Wong HY, Liu Q, Calvo K, Lai CE, Hourigan SS. Increased frequencies of PD-1+ CD8+ marrow-infiltrating lymphocytes associated with highly clonal t-lymphocyte expansions in relapsed and refractory aml patients but not healthy adults. Blood. 2016; 128(22):Abstract 1644.

130. Yang H, Bueso-Ramos C, DiNardo C, Estecio MR, Davanlou M, Geng QR, Fang Z, Nguyen M, Pierce S, Wei Y, et al. Expression of PD-L1, PD-L2, PD-1 and CTLA4 in myelodysplastic syndromes is enhanced by treatment with hypomethylating agents. Leukemia. 2014;28(6):1280-8.

131. Daver N, Basu S, Garcia-Manero G, Cortes J, Ravandi F, Ning J, Xiao L, Juliana L, Kornblau SM, Konopleva M et al: Defining the Immune Checkpoint Landscape in Patients (pts) with Acute Myeloid Leukemia (AML). Blood. 2016;128(22):Abstract 2900.

132. Zhou Q, Munger ME, Veenstra RG, Weigel BJ, Hirashima M, Munn DH, Murphy WJ, Azuma M, Anderson AC, Kuchroo VK, et al. Coexpression of Tim-3 and PD-1 identifies a CD8+ T-cell exhaustion phenotype in mice with disseminated acute myelogenous leukemia. Blood. 2011;117(17):4501-10.

133. Noviello M, Manfredi F, Perini T, Oliveira G, Cortesi F, Toffalori C, Gambacorta V, Bondanza A, Greco R, Peccatori J et al. Multiple inhibitory receptors are expressed on central memory and memory stem t cells infiltrating the bone marrow of aml patients relapsing after Allo-HSCT. Blood. 2016;128(22): Abstact 4564.

134. Ansell SM, Lesokhin AM, Borrello I, Halwani A, Scott EC, Gutierrez M, Schuster SJ, Millenson MM, Cattry D, Freeman GJ, et al. PD-1 blockade with nivolumab in relapsed or refractory Hodgkin's lymphoma. N Engl J Med. 2015;372(4):311-9.

135. Younes A, Santoro A, Zinzani PL, Timmerman J, Ansell SM, Armand P, Fanale MA, Ratanatharathorn V, Kuruvilla J, Cohen JB, et al. Checkmate 205: nivolumab (nivo) in classical Hodgkin lymphoma ( $\mathrm{CHL}$ ) after autologous stem cell transplant (ASCT) and brentuximab vedotin (BV) - A phase 2 study. J Clin Oncol. 2016;34(suppl):abstr 7535.

136. Younes A, Santoro A, Shipp M, Zinzani PL, Timmerman JM, Ansell S, Armand $P$, Fanale M, Ratanatharathorn V, Kuruvilla J, et al. Nivolumab for classical Hodgkin's lymphoma after failure of both autologous stem-cell transplantation and brentuximab vedotin: a multicentre, multicohort, singlearm phase 2 trial. Lancet Oncol. 2016;17(9):1283-94.

137. Timmerman J, Engert A, Younes A, Santoro A, Armand P, Fanale M, Collins GP, Ratanatharathorn V, Kuruvilla J, Cohen JB, et al. Checkmate 205 update with minimum 12-month follow up: a phase 2 study of nivolumab in patients with relapsed/refractory classical Hodgkin lymphoma. Blood. 2016; 128(22):Abstract 1110

138. Armand P, Shipp MA, Ribrag V, Michot JM, Zinzani PL, Kuruvilla J, Snyder ES, Ricart AD, Balakumaran A, Rose $S$ et al. Programmed death-1 blockade with pembrolizumab in patients with classical Hodgkin lymphoma after brentuximab vedotin failure. J Clin Oncol. 2016;34(31):3733-39.

139. Armand P, Shipp MA, Ribrag V, Michot JM, Zinzani PL, Kuruvilla J, Zhu Y, Ricart AD, Balakumaran A, Moskowitz CH. Pembrolizumab in patients with classical Hodgkin lymphoma after. Blood. 2016;128(22):Abstract 1108.

140. Chen RW, Zinzani PL, Fanale MA, Armand P, Johnson N, Ribrag V, Radford JA, Tomita A, Shipp MA, Wang Y, et al. Pembrolizumab for relapsed/ refractory classical Hodgkin lymphoma (R/R CHL): phase 2 KEYNOTE-087 study. J Clin Oncol. 2016:34(suppl):abstr 7555.

141. Moskowitz CH, Zinzani PL, Fanale M, Armand P, Johnson NA, Radford JA, Ribrag V, Molin D, Vassilakopoulos TP, Tomita A, et al. Pembrolizumab in relapsed/refractory classical Hodgkin lymphoma: primary end point analysis of the phase 2 Keynote-087 Study. Blood. 2016;128(22):Abstract 1107.

142. Zinzani PL, Ribrag V, Moskowitz CH, Michot JM, Kuruvilla J, Balakumaran A, Zhang Y, Marinello P, Chlostra S, Gustafson E, et al. Phase 1b study of pembrolizumab in patients with relapsed/refractory primary mediastinal large B-cell lymphoma: results from the ongoing Keynote-013 Trial. Blood. 2016;128(22):Abstact 619

143. Nayak L, Iwamoto F, LaCasce AS, Mukundan Jr S, Roemer MG, Chapuy B, Armand P, Rodig SJ, Shipp MA. Nivolumab (anti-PD1) therapy for relapsed/ refractory primary central nervous system lymphoma and primary testicular lymphoma. Blood. 2016;128(22):Abstract 930

144. Khodadoust M, Rook AH, Porcu P, Foss FM, Moskowitz AJ, Shustove AR Shanbhag S, Sokol L, Shine R, Fling SP, et al. Pembrolizumab for Treatment of relapsed/refractory mycosis fungoides and Sezary syndrome: clinical efficacy in a Citn multicenter phase 2 Study. Blood. 2016;128(22):Abstract 181

145. Lesokhin AM, Ansell SM, Armand P, Scott EC, Halwani A, Gutierrez M, Millenson MM, Cohen AD, Schuster SJ, Lebovic D, et al. Nivolumab in patients with relapsed or refractory hematologic malignancy: preliminary results of a phase ib study. J Clin Oncol. 2016;34(23):2698-704.

146. Till BG, Park SI, Popplewell LL, Goy A, Penuel E, Venstrom JM, Liu B, FingerleRowson G, Byon J, Woodard P, et al. Safety and clinical activity of atezolizumab (Anti-PDL1) in combination with obinutuzumab in patients 
with relapsed or refractory non-Hodgkin lymphoma. Blood. 2015;126(23): Abstract 5104.

147. Ansell SM, Hurvitz SA, Koenig PA, LaPlant BR, Kabat BF, Fernando D, Habermann TM, Inwards DJ, Verma M, Yamada R, et al. Phase I study of ipilimumab, an anti-CTLA-4 monoclonal antibody, in patients with relapsed and refractory B-cell non-Hodgkin lymphoma. Clin Cancer Res. 2009;15(20):6446-53.

148. Davids MS, Kim HT, Bachireddy P, Costello C, Liguori R, Savell A, Lukez AP, Avigan D, Chen YB, McSweeney P, et al. Ipilimumab for patients with relapse after allogeneic transplantation. N Engl J Med. 2016;375(2):143-53.

149. Ansell S, Gutierrez M, Shipp MA, Gladstone D, Moskowitz AJ, Borrello I, Popa-Mckiver M, Farsaci B, Zhu L, Lesokhin AM, et al. A Phase 1 Study of Nivolumab in Combination with Ipilimumab for Relapsed or Refractory Hematologic Malignancies (CheckMate 039). Blood. 2016;128(22):Abstract 183.

150. Mateos M-V, Orlowski RZ, Siegel DSD, Reece DE, Moreau P, Ocio EM, Shah $\mathrm{JJ}$, Rodríguez-Otero P, Munshi NC, Avigan D, et al. Pembrolizumab in combination with lenalidomide and low-dose dexamethasone for relapsed/ refractory multiple myeloma (RRMM): Final efficacy and safety analysis. J Clin Oncol. 2016;34(suppl):abstr 8010.

151. San Miguel J, Mateos M-V, Shah JJ, Ocio EM, Rodriguez-Otero P, Reece D, Munshi NC, Avigan DE, Ge Y, Balakumaran A, et al. Pembrolizumab in Combination with Lenalidomide and Low-Dose Dexamethasone for Relapsed/Refractory Multiple Myeloma (RRMM): Keynote-023. Blood. 2015; 126(23):Abstract 505.

152. Badros AZ, Hyjek E, Ma N, Lesokhin AM, Rapoport AP, Kocoglu MH, Lederer E, Philip S, Lesho P, Johnson A, et al. Pembrolizumab in Combination with pomalidomide and dexamethasone for relapsed/refractory multiple myeloma (RRMM). Blood. 2016;128(22):Abstract 490.

153. Wilson L, Cohen AD, Weiss B, Vogl DT, Garafall AL, Capozzi DL, Mangan P, Sanchez M, Erb C, Stadtmauer E. Pembrolizumab in combination with pomalidomide and dexamethasone (PEMBRO/POM/DEX) for pomalidomide exposed relapsed or refractory multiple Myeloma. Blood. 2016;128(22): Abstract 2119

154. Shah JJ, Jagannath S, Mateos M-V, Palumbo A, Kher U, Marinello P, San Miguel J. KEYNOTE-183: A randomized, open-label phase 3 study of pembrolizumab in combination with pomalidomide and low-dose dexamethasone in refractory or relapsed and refractory multiple myeloma (rrMM). J Clin Oncol. 2016;34(suppl):abstr TPS8070.

155. Palumbo A, Mateos M-V, San Miguel J, Shah JJ, Thompson S, Marinello P, Jagannath S. Pembrolizumab in combination with lenalidomide and lowdose dexamethasone in newly diagnosed and treatment-naive multiple myeloma (MM): randomized, phase 3 KEYNOTE-185 study. Ann Oncol. 2016;27(suppl_6):940Tip.

156. Bashey A, Medina B, Corringham S, Pasek M, Carrier E, Vrooman L, Lowy I, Solomon SR, Morris LE, Holland HK, et al. CTLA4 blockade with ipilimumab to treat relapse of malignancy after allogeneic hematopoietic cell transplantation. Blood. 2009;113(7):1581-8

157. Zeidan AM, Zeidner JF, Duffield A, Knaus HA, Ferguson A, Sheldon K, DeZern AE, Gojo I, Gore SD, Stericher H, et al. Stabilization of myelodysplastic syndromes (MDS) following hypomethylating agent (HMAs) failure using the immune checkpoint inhibitor ipilimumab: a phase I trial. Blood. 2015;126:1666.

158. Daver N, Basu S, Garcia-Manero G, Cortes J, Ravandi F, Jabbour EJ, Hendrickson S, Pierce S, Ning J, Konopleva M et al. Phase IB/II Study of nivolumab in combination with azacytidine (AZA) in patients (pts) with relapsed acute myeloid leukemia (AML). Blood. 2016;128(22):Abstract 763.

159. Garcia-Manero G, daver N, Montalban-Bravo G, Jabbour EJ, diNardo C, Kornblau SM, Bose P, Alvarado Y, Ohanian M, Borthakur G et al. A Phase II study evaluating the combination of nivolumab (nivo) or ipilimumab (Ipi) with azacitidine in pts with previously treated or untreated myelodysplastic syndromes (MDS). Blood. 2016;128(22):Abstract 344.

160. Garcia-Manero G, Tallman MS, Martinelli G, Ribrag V, Yang H, Balakumaran A, Chlosta S, Zhang Y, Smith BD. Pembrolizumab, a PD-1 Inhibitor, in patients with myelodysplastic syndrome (MDS) after failure of hypomethylating agent treatment. Blood. 2016;128(22):Abstract 345.

161. Naidoo J, Page DB, Li BT, Connell LC, Schindler K, Lacouture ME, Postow MA, Wolchok JD. Toxicities of the anti-PD-1 and anti-PD-L1 immune checkpoint antibodies. Ann Oncol. 2015;26(12):2375-91.
162. Horvat TZ, Adel NG, Dang TO, Momtaz P, Postow MA, Callahan MK, Carvajal RD, Dickson MA, D'Angelo SP, Woo KM, et al. Immune-related adverse events, need for systemic immunosuppression, and effects on survival and time to treatment failure in patients with melanoma treated with ipilimumab at memorial sloan kettering cancer center. J Clin Oncol. 2015;33(28):3193-8.

163. Weber JS, Hodi FS, Wolchok JD, Topalian SL, Schadendorf D, Larkin J, Sznol M, Long GV, Li H, Waxman IM, et al. Safety Profile of nivolumab monotherapy: a pooled analysis of patients with advanced melanoma. J Clin Oncol. 2017;35(7):785-92.

164. Postow MA, Chesney J, Pavlick AC, Robert C, Grossmann K, McDermott D, Linette GP, Meyer N, Giguere JK, Agarwala SS, et al. Nivolumab and ipilimumab versus ipilimumab in untreated melanoma. N Engl J Med. 2015;372(21):2006-17.

165. Larkin J, Chiarion-Sileni V, Gonzalez R, Grob JJ, Cowey CL, Lao CD, Schadendorf D, Dummer R, Smylie M, Rutkowski P, et al. Combined nivolumab and ipilimumab or monotherapy in untreated melanoma. N Engl J Med. 2015;373(1):23-34.

166. Gajewski TF. Cancer immunotherapy. Mol Oncol. 2012;6(2):242-50.

167. Topalian SL, Hodi FS, Brahmer JR, Gettinger SN, Smith DC, McDermott DF, Powderly JD, Carvajal RD, Sosman JA, Atkins MB, et al. Safety, activity, and immune correlates of anti-PD-1 antibody in cancer. N Engl J Med. 2012; 366(26):2443-54.

168. Roemer MG, Ligon AH, Engert A, Younes A, Santoro A, Zinzani PL, Timmerman J, Ansell S, Armand P, Fanale M et al. Chromosome 9p24.1/PD-L1/PD-L2 Alterations and PD-L1 Expression and Treatment Outcomes in Patients with Classical Hodgkin Lymphoma Treated with Nivolumab (PD-1 Blockade). Blood. 2016;128(22):Abstract 2923.

169. Rossille D, Gressier M, Damotte D, Maucort-Boulch D, Pangault C, Semana G, Le Gouill S, Haioun C, Tarte K, Lamy T, et al. High level of soluble programmed cell death ligand 1 in blood impacts overall survival in aggressive diffuse large B-Cell lymphoma: results from a French multicenter clinical trial. Leukemia. 2014:28(12):2367-75.

170. Powles T, Eder JP, Fine GD, Braiteh FS, Loriot Y, Cruz C, Bellmunt J, Burris HA, Petrylak DP, Teng SL, et al. MPDL3280A (anti-PD-L1) treatment leads to clinical activity in metastatic bladder cancer. Nature. 2014;515(7528):558-62.

171. Chen PL, Roh W, Reuben A, Cooper ZA, Spencer CN, Prieto PA, Miller JP, Bassett RL, Gopalakrishnan V, Wani K, et al. Analysis of immune signatures in longitudinal tumor samples yields insight into biomarkers of response and mechanisms of resistance to immune checkpoint blockade. Cancer Discov. 2016;6(8):827-37.

172. Streitz M, Miloud T, Kapinsky M, Reed MR, Magari R, Geissler EK, Hutchinson $J A$, Vogt K, Schlickeiser S, Kverneland AH, et al. Standardization of whole blood immune phenotype monitoring for clinical trials: panels and methods from the ONE study. Transplant Res. 2013;2(1):17.

173. Maecker HT, McCoy JP, Nussenblatt R. Standardizing immunophenotyping for the Human Immunology Project. Nat Rev Immunol. 2012;12(3):191-200.

174. Rizvi NA, Hellmann MD, Snyder A, Kvistborg P, Makarov V, Havel JJ, Lee W, Yuan J, Wong P, Ho TS, et al. Cancer immunology. Mutational landscape determines sensitivity to PD-1 blockade in non-small cell lung cancer. Science. 2015;348(6230):124-8.

175. Charoentong P, Finotello F, Angelova M, Mayer C, Efremova M, Rieder D, Hackl H, Trajanoski Z. Pan-cancer immunogenomic analyses reveal genotypeimmunophenotype relationships and predictors of response to checkpoint blockade. Cell Rep. 2017;18(1):248-62.

176. Hackl H, Charoentong P, Finotello F, Trajanoski Z. Computational genomics tools for dissecting tumour-immune cell interactions. Nat Rev Genet. 2016;17(8):441-58

177. Gubin MM, Zhang $X$, Schuster $H$, Caron E, Ward JP, Noguchi T, Ivanova $Y$, Hundal J, Arthur CD, Krebber WJ, et al. Checkpoint blockade cancer immunotherapy targets tumour-specific mutant antigens. Nature. 2014; 515(7528):577-81. 